\title{
Modeling the evolution of aerosol particles in a ship plume using PartMC-MOSAIC
}

\author{
J. Tian ${ }^{1}$, N. Riemer ${ }^{1}$, M. West ${ }^{2}$, L. Pfaffenberger ${ }^{3}$, H. Schlager ${ }^{4}$, and A. Petzold ${ }^{5}$ \\ ${ }^{1}$ Department of Atmospheric Sciences, University of Illinois at Urbana-Champaign, Urbana, Illinois, USA \\ ${ }^{2}$ Department of Mechanical Science and Engineering, University of Illinois at Urbana-Champaign, Urbana, Illinois, USA \\ ${ }^{3}$ Laboratory of Atmospheric Chemistry, Paul Scherrer Institute, 5232 Villigen, Switzerland \\ ${ }^{4}$ Dt. Zentrum für Luft- und Raumfahrt, Inst. für Physik der Atmosphäre, Oberpfaffenhofen, 82234 Wessling, Germany \\ ${ }^{5}$ Forschungszentrum Jülich GmbH, Institute of Energy and Climate Research, IEK-8-Troposphere, Jülich, Germany
}

Correspondence to: N. Riemer (nriemer@illinois.edu)

Received: 6 May 2013 - Published in Atmos. Chem. Phys. Discuss.: 21 June 2013

Revised: 19 March 2014 - Accepted: 11 April 2014 - Published: 3 June 2014

\begin{abstract}
This study investigates the evolution of shipemitted aerosol particles using the stochastic particleresolved model PartMC-MOSAIC (Particle Monte Carlo model-Model for Simulating Aerosol Interactions and Chemistry). Comparisons of our results with observations from the QUANTIFY (Quantifying the Climate Impact of Global and European Transport Systems) study in 2007 in the English Channel and the Gulf of Biscay showed that the model was able to reproduce the observed evolution of total number concentration and the vanishing of the nucleation mode consisting of sulfate particles. Further process analysis revealed that during the first hour after emission, dilution reduced the total number concentration by four orders of magnitude, while coagulation reduced it by an additional order of magnitude. Neglecting coagulation resulted in an overprediction of more than one order of magnitude in the number concentration of particles smaller than $40 \mathrm{~nm}$ at a plume age of 100 s. Coagulation also significantly altered the mixing state of the particles, leading to a continuum of internal mixtures of sulfate and black carbon. The impact on cloud condensation nuclei $(\mathrm{CCN})$ concentrations depended on the supersaturation threshold $S$ at which CCN activity was evaluated. For the base case conditions, characterized by a low formation rate of secondary aerosol species, neglecting coagulation, but simulating condensation, led to an underestimation of CCN concentrations of about $37 \%$ for $S=0.3 \%$ at the end of the 14-h simulation. In contrast, for supersaturations higher than $0.7 \%$, neglecting coagulation resulted in an overestimation of CCN concentration, about $75 \%$ for $S=1 \%$. For $S$ lower
\end{abstract}

than $0.2 \%$ the differences between simulations including coagulation and neglecting coagulation were negligible. $\mathrm{Ne}$ glecting condensation, but simulating coagulation did not impact the $\mathrm{CCN}$ concentrations below $0.2 \%$ and resulted in an underestimation of $\mathrm{CCN}$ concentrations for larger supersaturations, e.g., $18 \%$ for $S=0.6 \%$. We also explored the role of nucleation for the $\mathrm{CCN}$ concentrations in the ship plume. For the base case the impact of nucleation on $\mathrm{CCN}$ concentrations was limited, but for a sensitivity case with higher formation rates of secondary aerosol over several hours, the $\mathrm{CCN}$ concentrations increased by an order of magnitude for supersaturation thresholds above $0.3 \%$.

\section{Introduction}

Emissions from ocean-going ships have been receiving increased attention in recent years due to their adverse effects on coastal and global air quality (Ault et al., 2009; Endresen et al., 2003; González et al., 2011; Moldanová et al., 2009; Eyring et al., 2007), human health (Corbett et al., 2007; Winebrake et al., 2009) and the climate system (Capaldo et al., 1999; Eyring et al., 2010; Lawrence and Crutzen, 1999). Aerosol particles from ship exhaust represent a large fraction of global anthropogenic aerosol emissions (Agrawal et al., 2009; Dominguez et al., 2008) and influence significantly the radiative budget of the atmosphere both directly and indirectly (Capaldo et al., 1999). 
Ship-emitted particulates are a mix of different particle types. These include combustion particles consisting mainly of black carbon (BC), primary organic carbon (POC), sulfate and ash, and volatile particles forming from nucleation of sulfuric acid during plume expansion (Song et al., 2003; Cooper, 2003; Petzold et al., 2008). Their overall direct effect on the climate system is complex since BC causes a positive radiative forcing, while sulfuric acid particles cause a negative radiative forcing (Lauer et al., 2007; Kasper et al., 2007). While the different particle types are initially externally mixed, internal mixtures can form as a result of coagulation and condensation processes as the plume evolves, which may significantly alter the particles' optical properties and hence the magnitude of the direct climate impact (Durkee et al., 2000b; Jacobson et al., 2011). Particles from ship exhaust can also act as cloud condensation nuclei (CCN) and thus indirectly affect the climate by increasing cloud reflectivity (Twomey et al., 1968; Durkee et al., 2000a; Durkee et al., 2000b; Porch et al., 1999; Russell et al., 2000; Peters et al., 2012). The "ship tracks", shown as the curvilinear cloud structures observed in satellite images of marine cloud fields, in fact represented the first evidence of an indirect effect by ship emissions (Conover, 1966; Coakley et al., 1987). Similarly to the particles' optical properties, their CCN properties may change during the plume evolution, which in turn impacts their indirect effect.

Many studies have been conducted in the past decade to characterize ship emissions and their effects on climate through a combination of exhaust and plume measurements (Murphy et al., 2009; Frick and Hoppel, 2000; Petzold et al., 2008; Osborne et al., 2001; Sinha et al., 2003; Coggon et al., 2012). Healy et al. (2009) investigated the freshly-emitted ship exhaust particles on a single-particle level using an aerosol time-of-flight mass spectrometer (ATOFMS) at the Port of Cork, Ireland. They identified a unique ship exhaust particle type residing in the ultrafine mode and containing internally mixed elemental and organic carbon, sodium, calcium, iron, vanadium, nickel and sulfate. To quantify the in-plume mixing state Ault et al. (2010) conducted a series of individual ship plume measurements at the port of Los Angeles using a $4 \mathrm{~m}$ sampling mast at a site near the center of the main channel. The measurements characterized the size-resolved particle mixing state for individual plumes with plume ages ranging between $10-45 \mathrm{~min}$. Their study showed enhanced sulfate concentration in ship plumes, probably due to vanadium-catalyzed sulfate-production reactions in the plume within minutes of emission.

The evolution of ship-emitted particles has also been investigated in a number of modeling studies. Russell et al. (1999) applied an externally mixed, sectional aerosol dynamic model to characterize condensational and coagulational particle growth during the Monterey Area Ship Tracks (MAST) experiment in 1994 and found that the sulfur content of fuels used in combustion processes had a direct impact on the CCN properties. Later Erlick et al. (2001) applied the same model as described in Russell et al. (1999) together with a delta-Eddington exponential-sum-fit radiation algorithm to simulate aerosol-cloud-interaction during two ship track events in the MAST experiment. The results suggested that both the marine clouds and ship tracks enhanced atmospheric absorption with respect to a clear sky. Song et al. (2003) used a Lagrangian photochemical plume model to explore the in-plume sulfur chemistry and new particle formation. Their findings stressed the importance of photochemistry for the production of sulfuric acid particles in plumes. von Glasow et al. (2003) introduced a plume expansion scheme in a time dependent photochemical model based on an updated version of the box model MOCCA (Model Of Chemistry Considering Aerosols) (Sander and Crutzen, 1996; Vogt et al., 1996) to treat the mixing of background and plume air. The evolution of particles in the plume was tracked by considering dilution and chemical processes, while coagulation was neglected. The influence of semi-volatile background aerosol particles was found to be important for the in-plume gas phase chemistry, while including the soluble ship-produced aerosols was of little importance for in-plume heterogeneous reactions since dilution significantly reduced ship-derived particles on a very short time scale.

For this study we represented the evolving particle distribution of ship-emitted aerosols with a new modeling approach, the stochastic particle-resolved aerosol model PartMC-MOSAIC (Particle Monte Carlo model-Model for Simulating Aerosol Interactions and Chemistry) (Riemer et al., 2009). This model explicitly resolves the composition of individual particles in a given aerosol population and is therefore uniquely suited to investigate the evolution of particle mixing states and the associated particle properties. PartMC-MOSAIC has been used for detailed studies on the particle level, for example to derive aging time-scales of black carbon aerosol (Riemer et al., 2010), to investigate the heterogeneous oxidation of soot surfaces (Kaiser et al., 2011), to quantify the impacts of black carbon mixing state on black carbon nucleation scavenging (Ching et al., 2012), and to explore the sensitivity of cloud condensation nuclei activity to particle characteristics at emission (Fierce et al., 2013). It was also used as a modeling tool to explain the diurnal variations of aerosol hygroscopicity and the mixing state of light-absorbing carbonaceous material in the North China Plain (Liu et al., 2011; Ma et al., 2012).

The simulations for the present work were initialized with gas and particle information obtained from a test-rig study as part of the European research project HERCULES (Highefficiency Engine R\&D on Combustion with Ultra-Low Emissions for Ships) in 2006 using a serial four-stroke marine diesel engine operating on high-sulfur heavy fuel oil (Petzold et al., 2008). We then tracked the particle population for several hours as it evolved undergoing coagulation, dilution with the background air, and chemical transformations in the aerosol and gas phase. We compared the results to aircraft measurements made in the English Channel and 
the Gulf of Biscay (France) in 2007 as part of the European program QUANTIFY.

New particle formation (nucleation) may play an important role in the evolution of the ship plume particle population (Song et al., 2003). Significant uncertainties are associated with modeling nucleation and growth, both regarding the quantification of the nucleation rates (Lucas and Akimoto, 2006; Yli-Juuti et al., 2011; Pierce and Adams, 2009; Verheggen and Mozurkewich, 2002), as well as regarding the mechanism responsible for particle growth (Spracklen et al., 2008; Kulmala et al., 2004; Westervelt et al., 2013). Here we use the parameterization by Kuang et al. (2008) to investigate when and to what extent nucleation impacts $\mathrm{CCN}$ concentration in the plume. This paper does not attempt to exhaustively survey the range of currently proposed models for nucleation and subsequent particle growth.

The scientific contribution of this study is twofold. First, it is the first process study on the evolution of the particleresolved mixing state in ship plumes quantifying the roles of coagulation and condensation in the plume and their impact on CCN properties of the particles. Second, this study provides validation for PartMC-MOSAIC due to good agreement to field observations. The structure of this manuscript is as follows. Section 2 states the governing equations that form the basis of the model, and Sect. 3 describes the numerical methods. Section 4 shows the ship plume modeling results for the simulations, which did not consider nucleation. The result for the simulations considering nucleation are presented in Appendix A. Section 5 summarizes our major findings.

\section{Coupled equations governing gas-particle interactions}

Our modeling framework considers a Lagrangian parcel, which simulates the evolution of aerosol particles and trace gases that are emitted by the ship in a volume of air moving along a specified trajectory at the center of the plume. After leaving the exhaust stack the air parcel is not further influenced by emissions. In addition to coagulation and aerosol and gas chemistry within the plume, the model treats mixing of the parcel with background air. Inherent to the parcel modeling approach is the assumption that the plume is immediately well-mixed. Within the air parcel we do not track the physical location of aerosol particles, and we assume homogeneous meteorological conditions and gas concentrations. Concentration gradients across the plume cannot be resolved with this approach and would require the use of a spatiallyresolved 3-D model framework.

Assuming that an aerosol particle contains mass $\mu_{\mathrm{a}}>0$ (kg) of species $a$, for $a=1, \ldots, A$, the particle composition is described by the $A$-dimensional vector $\mu \in \mathbb{R}^{A}$. The cumulative aerosol number distribution at time $t$ and constituent masses $\boldsymbol{\mu} \in \mathbb{R}^{A}$ is $N(\boldsymbol{\mu}, t)\left(\mathrm{m}^{-3}\right)$, which is defined to be the number concentration of aerosol particles that contain less than $\mu_{\mathrm{a}}$ mass of species $a$, for all $a=1, \ldots, A$. The aerosol number distribution at time $t$ and constituent masses $\mu \in \mathbb{R}^{A}$ is $n(\mu, t)\left(\mathrm{m}^{-3} \mathrm{~kg}^{-A}\right)$, which is defined by

$n(\boldsymbol{\mu}, t)=\frac{\partial^{A} N(\boldsymbol{\mu}, t)}{\partial \mu_{1} \partial \mu_{2} \ldots \partial \mu_{A}}$.

We denote the concentration of trace gas phase species $i$ at time $t$ by $g_{i}(t)\left(\mathrm{mol} \mathrm{m}^{-3}\right)$, for $i=1, \ldots, G$, so the trace gas phase species concentrations are described by the $G$ dimensional vector $\boldsymbol{g}(t) \in \mathbb{R}^{G}$. We assume that the aerosol and gas species are numbered so that the first $C$ species of each undergo gas-to-particle conversion, and that they are in the same order so that gas species $i$ converts to aerosol species $i$, for $i=1, \ldots, C$. Besides, we further assume that aerosol species $C+1$ is water.

The complete set of differential equations governing the time evolution of the multidimensional aerosol size distribution with gas phase coupling in PartMC-MOSAIC is written in Eqs. (2) and (3).

$$
\begin{aligned}
\frac{\partial n(\boldsymbol{\mu}, t)}{\partial t} & =\underbrace{\frac{1}{2} \int_{0}^{\mu_{1}} \int_{0}^{\mu_{2}} \cdots \int_{0}^{\mu_{A}} K\left(\boldsymbol{\mu}^{\prime}, \boldsymbol{\mu}-\boldsymbol{\mu}^{\prime}\right) n\left(\boldsymbol{\mu}^{\prime}, t\right) n\left(\boldsymbol{\mu}-\boldsymbol{\mu}^{\prime}, t\right) \mathrm{d} \mu_{1}^{\prime} \mathrm{d} \mu_{2}^{\prime} \ldots \mathrm{d} \mu_{A}^{\prime}}_{\text {coagulation gain }} \\
& -\underbrace{\int_{0}^{\infty} \int_{0}^{\infty} \cdots \int_{0}^{\infty} K\left(\boldsymbol{\mu}, \boldsymbol{\mu}^{\prime}\right) n(\boldsymbol{\mu}, t) n\left(\boldsymbol{\mu}^{\prime}, t\right) \mathrm{d} \mu_{1}^{\prime} \mathrm{d} \mu_{2}^{\prime} \ldots \mathrm{d} \mu_{A}^{\prime}}_{\text {coagulation loss }} \\
& +\underbrace{\lambda_{\text {dil }}(t)\left(n_{\text {back }}(\boldsymbol{\mu}, t)-n(\boldsymbol{\mu}, t)\right)}_{\text {dilution }} \\
& -\underbrace{\sum_{i=1}^{C} \frac{\partial}{\partial \mu_{i}}\left(c_{i} I_{i}(\boldsymbol{\mu}, \boldsymbol{g}, t) n(\boldsymbol{\mu}, t)\right)}_{\text {gas-particle transfer }} \\
& +\underbrace{\frac{\partial}{\partial \mu_{C+1}\left(c_{\mathrm{W}} I_{\mathrm{w}}(\boldsymbol{\mu}, \boldsymbol{g}, t) n(\boldsymbol{\mu}, t)\right)}}_{\text {water transfer }} \\
& +\underbrace{\frac{1}{\rho_{\text {dry }}(t)} \frac{\mathrm{d} \rho_{\mathrm{dry}}(t)}{\mathrm{d} t} n(\boldsymbol{\mu}, t)}_{\text {air density change }}
\end{aligned}
$$




$$
\begin{aligned}
\frac{\mathrm{d} g_{i}(t)}{\mathrm{d} t} & =\underbrace{\lambda_{\text {dil }}(t)\left(g_{\text {back }, i}(t)-g_{i}(t)\right)}_{\text {dilution }}+\underbrace{R_{i}(\boldsymbol{g})}_{\text {chemical reactions }} \\
& +\underbrace{\frac{1}{\rho_{\text {dry }}(t)} \frac{\mathrm{d} \rho_{\text {dry }}(t)}{\mathrm{d} t} g_{i}(t)}_{\text {air density change }} \\
& -\underbrace{\int_{0}^{\infty} \cdots \int_{0}^{\infty} I_{i}(\boldsymbol{\mu}, \boldsymbol{g}, t) n(\boldsymbol{\mu}, t) \mathrm{d} \mu_{1} \mathrm{~d} \mu_{2} \ldots \mathrm{d} \mu_{A}}_{\text {gas-particle transfer }} \\
& -\underbrace{\frac{v_{\text {nuc }}^{\infty} \rho_{i}}{c_{i}} J_{\text {nuc }}(\boldsymbol{g}) \delta\left(i, i_{\mathrm{H}_{2} \mathrm{SO}_{4}}\right)}_{\text {nucleation }}
\end{aligned}
$$

In Eq. (2), $K\left(\boldsymbol{\mu}, \boldsymbol{\mu}^{\prime}\right)\left(\mathrm{m}^{3} \mathrm{~s}^{-1}\right)$ is the Brownian coagulation coefficient between particles with constituent masses $\boldsymbol{\mu}$ and $\boldsymbol{\mu}^{\prime}$ (see Riemer et al., 2009), $\lambda_{\text {dil }}(t)\left(\mathrm{s}^{-1}\right)$ is the dilution rate, $n_{\text {back }}(\mu t)\left(\mathrm{m}^{-3} \mathrm{~kg}^{-A}\right)$ is the background number distribution, $c_{i}\left(\mathrm{~kg} \mathrm{~mol}^{-1}\right)$ is the conversion factor from moles of gas species $i$ to mass of aerosol species $i$ (with $c_{\mathrm{W}}$ the factor for water), $I_{i}(\boldsymbol{\mu}, \boldsymbol{g}, t)\left(\mathrm{mol} \mathrm{s}^{-1}\right)$ is the condensation flux of gas species $i$ (with $I_{\mathrm{W}}(\boldsymbol{\mu}, \boldsymbol{g}, t)$ the flux for water), $J_{\text {nuc }}(\boldsymbol{g})$ $\left(\mathrm{m}^{-3} \mathrm{~s}^{-1}\right)$ is the formation rate of particles by nucleation, $\delta$ is the Kronecker delta function, $\boldsymbol{\mu}_{\text {nuc }}$ represents the particle composition vector of each nucleated particle. In Eq. (3), $g_{\text {back }, i}(t)\left(\mathrm{mol} \mathrm{m}^{-3}\right)$ is the background concentration of gas species $i, R_{i}(g)\left(\mathrm{mol} \mathrm{m}^{-3} \mathrm{~s}^{-1}\right)$ is the concentration growth rate of gas species $i$ due to chemical reactions in the gas phase, $\rho_{\text {dry }}(t)\left(\mathrm{kg} \mathrm{m}^{-3}\right)$ is the dry air density (with $\rho_{i}$ the density of gas species $i)$, and $v_{\text {nuc }}\left(\mathrm{m}^{3}\right)$ is the volume of each nucleated particle. The relevant references regarding the numerical implementation are provided in Sect. 3 .

\subsection{Model treatment of dilution}

To model the dilution process we followed von Glasow et al. (2003) who proposed a Gaussian plume dispersion model for the evolution of the plume in the horizontal and vertical directions. The time-dependent plume width $w_{\mathrm{pl}}(t)$ and height $h_{\mathrm{pl}}(t)$ are described by two power laws as

$$
\begin{aligned}
& w_{\mathrm{pl}}(t)=w_{0}\left(\frac{t+t_{0}}{t_{0}}\right)^{\alpha}, \\
& h_{\mathrm{pl}}(t)=h_{0}\left(\frac{t+t_{0}}{t_{0}}\right)^{\beta},
\end{aligned}
$$

where $w_{0}$ and $h_{0}$ are the dimensions of the plume at the start of the simulation. Note that compared to the formulation in von Glasow et al. (2003) we introduced $t_{0}$ in the numerator to avoid a singularity for $t=0$ in the expression for the dilution rate below. The coefficients $\alpha$ and $\beta$ are the plume expansion parameters in the horizontal and vertical, respectively. Assuming the plume cross section is semi-elliptic and is given as $A_{\mathrm{pl}}=(\pi / 8) w_{\mathrm{pl}} h_{\mathrm{pl}}$, the dilution rate $\lambda_{\text {dil }}(t)$ is:
$\lambda_{\mathrm{dil}}(t)=\frac{1}{A_{\mathrm{pl}}} \frac{\mathrm{d} A_{\mathrm{pl}}}{\mathrm{d} t}=\frac{\alpha+\beta}{t+t_{0}}$.

Previous ship plume studies have estimated the plume width and height at a plume age of $1 \mathrm{~s}$ to be approximately 10 and $5.5 \mathrm{~m}$, respectively (von Glasow et al., 2003; Durkee et al., 2000a; Ferek et al., 1998), and we used these values for $t_{0}$, $w_{0}$ and $h_{0}$, respectively. The parameters $\alpha=0.75$ and $\beta=0.6$ are the "best guesses" estimated from the expansion of ship tracks reported in the literature (von Glasow et al., 2003; Durkee et al., 2000a) and confirmed by observations reported in Petzold et al. (2008). von Glasow et al. (2003) evaluated the influence of mixing by varying $\alpha$ between 0.62 and 1 . The value of $\alpha=0.62$ was deemed unrealistic as it caused a strong and persistent separation between plume and background air, which is not expected to occur in the marine boundary layer. Values of $\alpha>0.82$ caused very strong mixing, most likely only valid in extremely turbulent conditions. From this von Glasow et al. (2003) concluded that $\alpha=0.75$ was appropriate to characterize the plume dispersion. Petzold et al. (2008) derived the values of $\alpha$ and $\beta$ by fitting simulated excess $\mathrm{CO}_{2}$ as a function of plume age to the observed data. The result of $\alpha=0.74$ to 0.76 agreed well with the "best guess" from von Glasow et al. (2003), while their result for $\beta=0.70$ to 0.80 was somewhat higher. While we will use the values of $\alpha=0.75$ and $\beta=0.6$ for our base case, we will also explore the sensitivity to changes in these parameters in Sect. 4.2 below.

We further assume the top of the marine boundary layer to be impenetrable by the plume and define $z_{\mathrm{MBL}}$ as the height of the marine boundary layer. The total dilution rate used in our ship plume simulation is then written as

$\lambda_{\mathrm{dil}}(t)=\left\{\begin{array}{cl}\frac{\alpha+\beta}{t+t_{0}} & h_{\mathrm{pl}}(t)<z_{\mathrm{MBL}} \\ \frac{\alpha}{t+t_{0}} & h_{\mathrm{pl}}(t)=z_{\mathrm{MBL}}\end{array}\right.$

\subsection{Model treatment of nucleation}

To model the nucleation process we follow the parameterization proposed by Kuang et al. (2008) based on the concentration of sulfuric acid. This uses a power law to quantify the production rate of nucleated particles as follows:

$J_{\text {nuc }}=K \cdot\left[\mathrm{H}_{2} \mathrm{SO}_{4}\right]^{P}$.

The values of prefactor $K$ and exponent $P$ in our model framework are $10^{-18} \mathrm{~m}^{3} \mathrm{~s}^{-1}$ and 2 , respectively, based on least squares fitting between the measured formation rate and corresponding sulfuric acid vapor concentrations at different atmospheric environments as described in Kuang et al. (2008). The rate $J_{\text {nuc }}$ quantifies the production of particles of diameter $1 \mathrm{~nm}$, which initially consist of sulfuric acid. 


\section{Numerical implementation}

The detailed description of the numerical methods used in PartMC-MOSAIC is given in Riemer et al. (2009). Here we briefly introduce the salient features of the model. PartMC (Particle-resolved Monte Carlo) is a 0-D, or box model, which explicitly resolves the composition of many individual particles within a well-mixed computational volume representing a much larger air parcel. During the evolution of the air parcel moving along a specific trajectory, the mass of each constituent species within each particle is tracked. Emission, dilution, nucleation and Brownian coagulation are simulated with a stochastic Monte Carlo approach. The relative positions of particles within the computational volume are not tracked.

PartMC is coupled with the state-of-the-art aerosol chemistry model MOSAIC (Model for Simulating Aerosol Interactions and Chemistry) (Zaveri et al., 2008) which includes the gas phase photochemical mechanism CBM-Z (Zaveri and Peters, 1999), the Multicomponent Taylor Expansion Method (MTEM) for estimating activity coefficients of electrolytes and ions in aqueous solutions (Zaveri et al., 2005b), the multi-component equilibrium solver for aerosols (MESA) for intraparticle solid-liquid partitioning (Zaveri et al., 2005a) and the adaptive step time-split Euler method (ASTEM) for dynamic gas-particle partitioning over sizeand composition-resolved aerosol (Zaveri et al., 2008), as well as a treatment for SOA (secondary organic aerosol) based on the SORGAM scheme (Schell et al., 2001). The CBM-Z gas phase mechanism treats a total of 77 gas species. MOSAIC treats key aerosol species including sulfate $\left(\mathrm{SO}_{4}\right)$, nitrate $\left(\mathrm{NO}_{3}\right)$, ammonium $\left(\mathrm{NH}_{4}\right)$, chloride $(\mathrm{Cl})$, carbonate $\left(\mathrm{CO}_{3}\right)$, methanesulfonic acid (MSA), sodium ( $\left.\mathrm{Na}\right)$, calcium (Ca), other inorganic mass (OIN), BC, POC, and SOA. OIN represents species such as $\mathrm{SiO}_{2}$, metal oxides, and other unmeasured or unknown inorganic species present in aerosols. SOA includes reaction products of aromatic precursors, higher alkenes, $\alpha$-pinene and limonene.

A challenge of particle-resolved models is the large computational burden when simulating the evolution of particles under ambient conditions. Particle size distributions usually cover a very broad size range from a few nanometers to tens of micrometers, and typically the number concentrations of the small particles compared to the large particles differ by several orders of magnitude. Both sub-populations are important as the small particles dominate particle number concentration whereas the large particles dominate particle mass concentrations. Moreover, the most likely coagulation events involve interactions of small and large particles. It is challenging to represent such a particle distribution with a particle-resolved model, so that the large, rare particles are sufficiently resolved, while the overall number of computational particles is still manageable. Here we used the method by DeVille et al. (2011) to reduce the computational cost and improve the model efficiency. This method is based on the notion that a single computational particle can correspond to some number of real particles, in other words, each computational particle is "weighted" by an appropriate factor. With this approach it is possible to span the large range of sizes and abundances of the particle population as will be demonstrated in Sect. 4.

We used model version PartMC 2.2.0 for this study. We initialized all simulations with $10^{5}$ computational particles. To capture the aerosol dynamics during early plume ages, when the particle number concentration rapidly decayed owing to coagulation and dilution, we used a time step of $0.2 \mathrm{~s}$ for the first $600 \mathrm{~s}$ of simulation time, and a time step of $60 \mathrm{~s}$ for the remainder of the simulation.

\subsection{Aerosol distribution functions}

While the underlying multidimensional aerosol distribution is defined in Eq. (1), we often project this distribution in appropriate ways to better display the results. We take $N(D)$ to be the cumulative number distribution, giving the number of particles per volume that have diameter less than $D$. We then define the number distribution $n(D)$ by

$n(D)=\frac{\mathrm{d} N(D)}{\mathrm{d}_{\log _{10} D} .}$

The underlying particle initial and background number size distributions used in our study were all superpositions of $\log$ normal distributions, each defined by

$n(D)=\frac{N}{\sqrt{2 \pi} \log _{10} \sigma_{\mathrm{g}}} \exp \left(-\frac{\left(\log _{10} D-\log _{10} D_{\mathrm{g}}\right)^{2}}{2\left(\log _{10} \sigma_{\mathrm{g}}\right)^{2}}\right)$,

where $N$ is the total number concentration, $D_{\mathrm{g}}$ is the geometric mean diameter, and $\sigma_{\mathrm{g}}$ is the geometric standard deviation.

To characterize the particle mixing state, we refer to the mass fraction of a species $a$ as

$w_{\mathrm{a}, \mathrm{dry}}=\frac{\mu_{\mathrm{a}}}{\mu_{\mathrm{dry}}}$,

where $\mu_{\mathrm{a}}$ is the mass of species $a$ in the particle, and $\mu_{\mathrm{dry}}$ is the total dry mass of the particle. We can then define a twodimensional number distribution that is a function of both particle composition and diameter. The two-dimensional cumulative number distribution $N_{\mathrm{a}, \mathrm{dry}}(D, w)$ is the number of particles per volume that have a diameter less than $D$ and a dry-mass fraction less than $w$ for certain species $a$. Here $a$ could be BC, POC, sulfate, nitrate, etc. The two-dimensional number distribution $n_{\mathrm{a}, \mathrm{dry}}(D, w)$ is then defined by

$n_{\mathrm{a}, \mathrm{dry}}(D, w)=\frac{\partial^{2} N_{\mathrm{a}, \mathrm{dry}}(D, w)}{\partial \log _{10} D \partial w}$.

To investigate changes in the $\mathrm{CCN}$ properties of the aerosols, we use the hygroscopicity parameter $\kappa$ to define a twodimensional cumulative number distribution $N_{\kappa}(D, \kappa)$ in 
terms of diameter and hygroscopicity parameter. Then the two-dimensional number distribution is written as

$n_{\kappa}(D, \kappa)=\frac{\partial^{2} N_{\kappa}(D, \kappa)}{\partial \log _{10} D \partial \log _{10} \kappa}$.

\subsection{CCN activity module}

The unique feature of PartMC-MOSAIC to provide particleresolved mixing state information enables us to calculate the critical supersaturation $S_{\mathrm{c}, i}$ that an individual particle requires to activate. The procedure is as follows. The perparticle water activity $a_{\mathrm{w}, i}$ is given by

$\frac{1}{a_{\mathrm{w}, i}}=1+\kappa_{i} \frac{V_{\mathrm{dry}, i}}{V_{\mathrm{w}, i}}$,

where $\kappa_{i}$ is a single, dimensionless hygroscopicity parameter to relate particle dry diameter to CCN activity (Ghan et al., 2001; Petters and Kreidenweis, 2007), $V_{\text {dry }, i}$ is the dry particle volume and $V_{\mathrm{w}, i}$ is the volume of water in the particle. For an aerosol particle $i$ containing several non-water species, the $\kappa_{i}$ value for the particle is the volume-weighted mean of the individual $\kappa$ value of each constituent species (Petters and Kreidenweis, 2007). Table 1 lists $\kappa$ values for individual aerosol components used in this study. The equilibrium saturation ratio $S\left(D_{i}\right)$ over an aqueous particle $i$ is given by the Köhler equation:

$S\left(D_{i}\right)=a_{\mathrm{w}, i} \exp \left(\frac{4 \sigma_{\mathrm{w}} M_{\mathrm{w}}}{R T \rho_{\mathrm{w}} D_{i}}\right)$,

where $\sigma_{\mathrm{W}}$ is the surface tension of the solution-air interface, $M_{\mathrm{W}}$ is the molecular weight of water, $R$ is the universal gas constant, $T$ is the temperature, and $D_{i}$ is the particle wet diameter. Combining Eqs. (14) and (15) and using wet and dry diameters $D_{i}$ and $D_{\mathrm{dry}, i}$ to represent their respective volumes, we obtain the $\kappa$-Köhler equation based on Petters and Kreidenweis (2007):

$S\left(D_{i}\right)=\frac{D_{i}^{3}-D_{\mathrm{dry}, i}^{3}}{D_{i}^{3}-D_{\mathrm{dry}, i}^{3}\left(1-\kappa_{i}\right)} \exp \left(\frac{4 \sigma_{\mathrm{w}} M_{\mathrm{w}}}{R T \rho_{\mathrm{w}} D_{i}}\right)$.

To calculate the critical supersaturation, we set $\partial S\left(D_{i}\right) / \partial D_{i}$ to zero and numerically solve for the critical wet diameter $D_{i}$, then use Eq. (16) to obtain the critical supersaturation $S_{\mathrm{c}, i}$ for each particle.

\subsection{Setup of case study}

Measurements of the particle and gas phase of the raw engine exhaust served as initial input parameters for our model runs. To evaluate our model, the output was compared to measurements performed in a single ship plume and in a ship corridor study. The two campaigns, HERCULES and QUANTIFY are briefly described in the following section.

The initial concentrations of gases and particles as well as particle size distribution and composition were obtained
Table 1. Hygroscopicity values, $\kappa$, for individual model species.

\begin{tabular}{ll}
\hline Species & Hygroscopicity, $\kappa$ \\
\hline $\mathrm{H}_{2} \mathrm{SO}_{4}$ & 0.9 \\
$\mathrm{NH}_{4} \mathrm{HSO}_{4}$ & 0.65 \\
$\mathrm{NH}_{4} \mathrm{NO}_{3}$ & 0.65 \\
$\mathrm{NaCl}$ & 1.12 \\
$\mathrm{POC}$ & 0.001 \\
$\mathrm{SOA}$ species & 0.1 \\
BC & 0.0 \\
Ash & 0.1 \\
\hline
\end{tabular}

from the HERCULES study in 2006 during which a serial four stroke marine diesel engine was used on a test rig (Petzold et al., 2008; Petzold et al., 2010). The heavy fuel oil was composed of $86.9 \mathrm{wt} \%$ carbon, $10.4 \mathrm{wt} \%$ hydrogen, $2.21 \mathrm{wt} \%$ sulfur, and some minor constituents. We used the exhaust data under $75 \%$ engine load condition for our model inputs. These exhaust conditions are expected to be similar to the ones encountered in the QUANTIFY study, therefore the aerosol population and the gas phase concentrations present in the engine exhaust served as input for the model.

During the QUANTIFY field study in June 2007, airborne measurements of a single ship plume (14 June 2007) as well as aged aerosol in highly frequented sea lanes (11 June 2007) were performed. During the single-plume study, the plume was crossed several times during the time interval of approximately one hour. As in-plume total particle number concentrations we considered the maximum measured concentration during one plume crossing $(D>4 \mathrm{~nm})$. Size distributions of both the polluted and the clean marine boundary layer were determined using a combination of instruments capable of measuring in different size ranges. The research domain with the flight path for 11 June is shown in Fig. 1. The location of the shipping corridor is marked. In addition to the size distributions observed in the shipping corridor, we also used measurements of gas phase species ( $\mathrm{NO}, \mathrm{NO}_{\mathrm{y}}, \mathrm{O}_{3}$, $\mathrm{SO}_{2}$, and $\mathrm{CO}$ ) to qualitatively compare to our simulations. Last but not least, the following meteorological parameters in the well-mixed marine boundary layer were measured and used for the model runs: a relative humidity of $\mathrm{RH}=90 \%$, a temperature $T=289 \mathrm{~K}$ and a boundary layer mixing height $z_{\mathrm{MBL}}=300 \mathrm{~m}$. These parameters were obtained from observations on 14 June 2007. The mixing height was derived from the vertical potential temperature profile.

Table 2 shows the initial and background conditions of the gaseous species obtained from the measurements during the HERCULES and QUANTIFY study, respectively. From the HERCULES measurements only the total amount of nonmethane hydrocarbons (NMHC) was known. We partitioned the total mixing ratio of NMHCs to different categories based on the composition fractions provided in Eyring et al. (2005), including (1) hexanes and higher alkanes, (2) ethene, 
Table 2. Gas phase initial and background conditions.

\begin{tabular}{|c|c|c|c|c|}
\hline \multicolumn{2}{|c|}{ Ship-engine exhausts ${ }^{a}$} & \multicolumn{3}{|c|}{ Model inputs } \\
\hline $\begin{array}{l}\text { Measured } \\
\text { species }\end{array}$ & Conc. (ppbV) & $\begin{array}{l}\text { CBM-Z } \\
\text { species }^{b}\end{array}$ & $\begin{array}{l}\text { Initial } \\
(\mathrm{ppbV}, \mathrm{ppbC})^{\mathrm{c}}\end{array}$ & $\begin{array}{l}\text { Background } \\
(\mathrm{ppbV}, \mathrm{ppbC})^{\mathrm{d}}\end{array}$ \\
\hline $\mathrm{NO}_{\mathrm{x}}$ & $9.14 \times 10^{5}$ & NO & $8.77 \times 10^{5}$ & $1.86 \times 10^{-2}$ \\
\hline $\mathrm{CO}$ & $3.4 \times 10^{4}$ & $\mathrm{NO}_{2}$ & $3.7 \times 10^{4}$ & $3.95 \times 10^{-2}$ \\
\hline $\mathrm{SO}_{2}$ & $4.7 \times 10^{5}$ & $\mathrm{HNO}_{3}$ & 0 & $3.29 \times 10^{-1}$ \\
\hline \multirow[t]{10}{*}{ NMHC } & $1.39 \times 10^{5}$ & $\mathrm{O}_{3}$ & 0 & $3.39 \times 10^{1}$ \\
\hline & & $\mathrm{CO}$ & $3.4 \times 10^{4}$ & $1.05 \times 10^{2}$ \\
\hline & & $\mathrm{SO}_{2}$ & $4.7 \times 10^{5}$ & $1.55 \times 10^{-1}$ \\
\hline & & $\mathrm{HCl}$ & 0 & $5.99 \times 10^{-1, \mathrm{e}}$ \\
\hline & & PAR & $3.09 \times 10^{5}$ & 2.46 \\
\hline & & ETH & $2.94 \times 10^{4}$ & 1.37 \\
\hline & & OLET & $3.38 \times 10^{4}$ & $5.1 \times 10^{-2}$ \\
\hline & & OLEI & $1.55 \times 10^{3}$ & $5.0 \times 10^{-3}$ \\
\hline & & TOL & $2.56 \times 10^{4}$ & $1.6 \times 10^{-2}$ \\
\hline & & XYL & $6.06 \times 10^{3}$ & $1.5 \times 10^{-2}$ \\
\hline
\end{tabular}

a Ship exhaust data are obtained from HERCULES measurement in 2006 under $75 \%$ engine load condition (Petzold et al., 2008; Petzold et al., 2010). NMHC refers to non-methane hydrocarbon. ${ }^{b}$ PAR, ETH, OLET, OLEI, TOL, XYL stand for paraffin carbon, ethene, terminal olefin carbons, internal olefin carbons, toluene and xylene, respectively. ${ }^{\mathrm{c}}$ Initial data are based on HERCULES measurement data. A $\mathrm{NO}: \mathrm{NO}_{2}$ ratio of $96: 4$ is assumed for the ship exhaust (von Glasow et al., 2003). The attribution of non-methane hydrocarbons are based on Table 2 in Eyring et al. (2005). The units of inorganic and organic species are ppbV and ppbC, respectively. ${ }^{\mathrm{d}}$ Values of background inorganic species are obtained from European program QUANTIFY in 2007. $\mathrm{NO}_{\mathrm{x}}$ to $\mathrm{NO}_{\mathrm{y}}$ ratio is 0.15 based on Table 2 in Shon et al. (2008) in the marine boundary layer. Organic species mixing ratios are based on measurements while approaching the UK from the west on 8 July 1988 (Penkett et al., 1993). ${ }^{\mathrm{e}}$ Value from Table 2 in Keene et al. (2007).

(3) propene, (4) toluene, (5) xylene, (6) trimethylbenzenes and (7) other alkene. We then converted these mixing ratios to model surrogate species mixing ratios as listed in Table 2 suitable for the use in CBM-Z. Note that CBM-Z is a carbon bond mechanism, and the model species represent the mixing ratios of constituent groups regardless of the molecule to which they are attached (Stockwell et al., 2012). The background inorganic gas phase mixing ratios in Table 2 were obtained by averaging the values along the segment of the flight track as marked in Fig. 1. This segment was outside the shipping corridor, and sampled at low enough altitude. The background NHMC concentrations were estimated from measurements by Penkett et al. (1993). They were taken on 8 July 1988, while approaching the UK from the west (with similar time and location to the QUANTIFY measurements). The measured species were converted to CBM-Z species including PAR, ETH, OLET, OLEI, TOL and XYL.

Table 3 shows the total number concentration, count median diameter and geometric standard deviation, the parameters determining the initial, background and ship corridor size distributions. The initial aerosol size distribution from the test rig study was composed of three distinct modes with one volatile nucleation mode and two larger combustion modes. The volatile mode consisted of $100 \%$ sulfate, while $\mathrm{BC}, \mathrm{POC}$ and ash were present in the two combustion modes. The background aerosol distribution was tri-modal

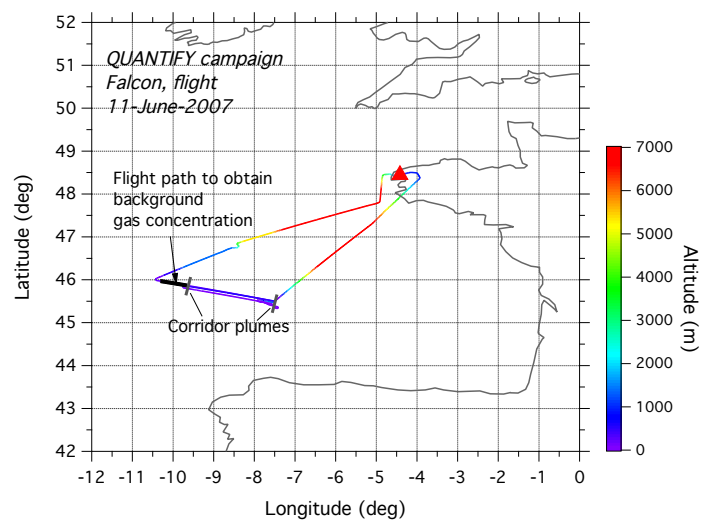

Figure 1. Map of research domain with flight path for 11 June 2007. The section of the flight path marked with "corridor plumes" marks the section of the path where the shipping corridor was sampled. Also marked is the section of the path that was used to obtain the background gas concentration (see Sect. 3.3 and Table 2 for details).

with Aitken, accumulation and coarse modes. We assigned the fractions of sulfate, ammonium, nitrate, $\mathrm{POC}, \mathrm{BC}$ and sea salt to these three modes based on O'Dowd and De Leeuw (2007).

We initialized our model with $10^{5}$ computational particles and followed the air parcel as it evolved for $14 \mathrm{~h}$ to predict the 
Table 3. Aerosol initial, background and ship corridor conditions ${ }^{\mathrm{a}}$.

\begin{tabular}{|c|c|c|c|c|}
\hline Initial & $N\left(\mathrm{~m}^{-3}\right)$ & $D_{\mathrm{g}}(\mathrm{nm})$ & $\sigma_{\mathrm{g}}$ & $\begin{array}{l}\text { Composition by Mass } \\
\text { (hygroscopicity, } \kappa \text { ) }\end{array}$ \\
\hline Volatile mode & $2.29 \times 10^{15}$ & 15 & 1.66 & $100 \% \mathrm{SO}_{4}(0.9)$ \\
\hline Combustion mode 1 & $4.36 \times 10^{14}$ & 38 & 1.40 & $11.7 \% \mathrm{BC}+88.3 \% \mathrm{POC}(0.0009)$ \\
\hline Combustion mode 2 & $3.11 \times 10^{10}$ & 155 & 1.25 & $27.6 \% \mathrm{Ash}+8.4 \% \mathrm{BC}+64.0 \% \mathrm{POC}(0.014)$ \\
\hline Background & $N\left(\mathrm{~m}^{-3}\right)$ & $D_{\mathrm{g}}(\mathrm{nm})$ & $\sigma_{\mathrm{g}}$ & $\begin{array}{l}\text { Composition by Mass }{ }^{b} \\
\text { (hygroscopicity, } \kappa \text { ) }\end{array}$ \\
\hline Aitken mode & $9.6 \times 10^{8}$ & 40 & 1.7 & $\begin{array}{l}9 \% \mathrm{SO}_{4}+2 \% \mathrm{NH}_{4}+1 \% \mathrm{NO}_{3} \\
+82 \% \text { POC }+2 \% \mathrm{BC}+4 \% \text { Sea salt }(0.07)\end{array}$ \\
\hline Accumulation mode & $2.3 \times 10^{8}$ & 200 & 1.25 & $\begin{array}{l}22 \% \mathrm{SO}_{4}+6 \% \mathrm{NH}_{4}+1 \% \mathrm{NO}_{3}+ \\
64 \% \mathrm{POC}+1 \% \mathrm{BC}+6 \% \text { Sea salt }(0.163)\end{array}$ \\
\hline Coarse mode & $3.2 \times 10^{6}$ & 900 & 1.8 & $\begin{array}{l}1 \% \mathrm{NO}_{3}+5 \% \mathrm{POC}+94 \% \\
\text { Sea salt }(0.999)\end{array}$ \\
\hline Ship corridor & $N\left(\mathrm{~m}^{-3}\right)$ & $D_{\mathrm{g}}(\mathrm{nm})$ & $\sigma_{\mathrm{g}}$ & Composition by Mass \\
\hline Aitken mode & $7.7 \times 10^{10}$ & 60 & 1.6 & \\
\hline Accumulation mode & $1.8 \times 10^{8}$ & 220 & 1.25 & \\
\hline
\end{tabular}

aged plume and to compare to measurements from the ship corridor. For the base case, the simulation started at 14:00 LT, similar to the measurement time of the single plume study on 14 June 2007. During the plume evolution we considered the following processes: dilution with the background air, coagulation of the particles, chemical transformations in the aerosol and gas phase, and phase transitions.

Coagulation and condensation may physically or thermodynamically change the particles' composition and phase state, and consequently alter the $\mathrm{CCN}$ activation properties. To quantify the impact of coagulation and condensation, we carried out two additional simulations, one where coagulation was not simulated (referred to as "only cond."), and one where chemical transformations were not simulated (referred to as "only coag.").

We also simulated a sensitivity case by setting the model starting time to 06:00 LT instead of 14:00 LT, to investigate conditions with a longer exposure to sunlight and hence more opportunity for secondary aerosol mass formation. Analogous to the base case we performed three runs: "cond. + coag.", “only cond.", and "only coag.".

To investigate the impact of new particle formation on $\mathrm{CCN}$ properties in the ship plume, we additionally performed simulations including nucleation as described in Sect. 2.2, and the simulation results will be discussed separately in the Appendix.

Due to the stochastic nature of PartMC-MOSAIC, for each simulation we conducted an ensemble of 10 runs and averaged the results of these runs to obtain more robust statistics.
To quantify the variability within this ensemble, we show the $95 \%$ confidence interval for the size distributions in Figs. 4 and 5 below.

\section{Results and discussion}

In this section we present the results of our base case simulation of the ship plume (start at 14:00 LT), and contrast it with the sensitivity case (start at 06:00 LT). To provide context, we begin by discussing the simulated evolution of selected trace gas species and bulk aerosol species. We then show the comparison of measured and modeled total number concentrations from a single plume event, as well as the comparison of measured and modeled size distributions from the shipping corridor. Finally, we quantify the role of coagulation and condensation for the evolution of aerosol mixing state and their impacts on $\mathrm{CCN}$ properties.

\subsection{Evolution of gas and bulk aerosol species}

Figure 2 shows the evolution of key trace gas mixing ratios and bulk aerosol species concentrations in the ship plume as it evolves for $14 \mathrm{~h}$. For our base case (start at 14:00 LT), dilution reduced the concentrations of the primary emitted species by several orders of magnitude within the first 1520 min of simulation time. Ozone was diluted in from the background air. For the base case the transition from day to night occurred at about $6 \mathrm{~h}$ after the simulation started. The $\mathrm{NO}_{2}$ mixing ratio was further decreased after $6 \mathrm{~h}$. While 

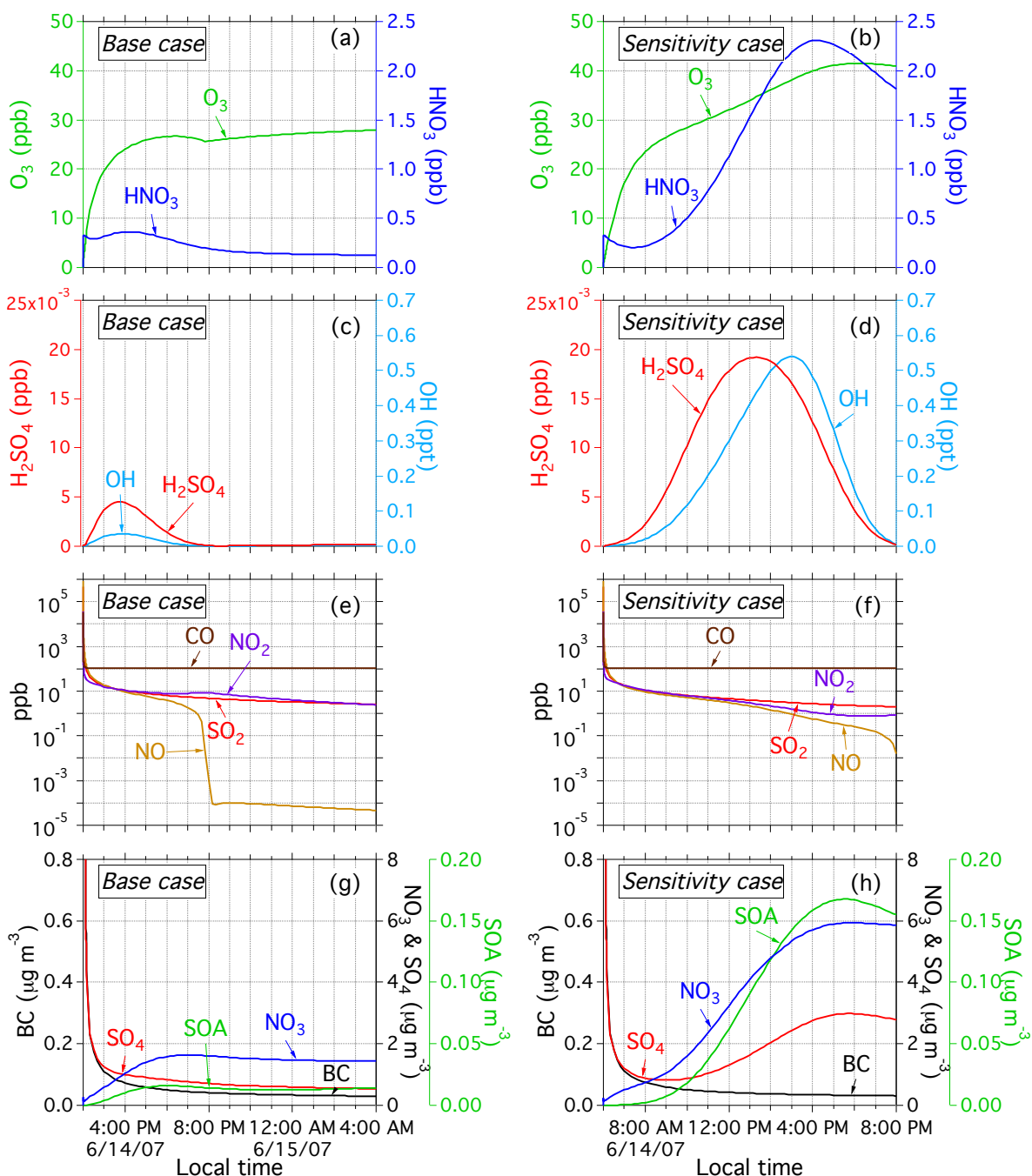

Figure 2. Evolution of gas and bulk aerosol species in the ship plume over a period of $14 \mathrm{~h}$ for the base case starting from 14:00 LT (left column panels) and sensitivity case starting from 06:00 LT (right column panels).

during nighttime the reaction of $\mathrm{NO}_{2}$ with $\mathrm{OH}$ ceases, $\mathrm{N}_{2} \mathrm{O}_{5}$ and $\mathrm{NO}_{3}$ are formed. In addition, reactions of $\mathrm{NO}_{3}$ with volatile organic compounds deplete $\mathrm{NO}_{\mathrm{x}}$ further.

The $\mathrm{OH}$ mixing ratio reached about $0.03 \mathrm{ppt}$ after $2 \mathrm{~h}$ of simulation and decreased later in the afternoon. The $\mathrm{HNO}_{3}$ mixing ratio reached quickly its background value within the first $10 \mathrm{~min}$, then showed a slight increase during daytime as a result of photochemical processes, and a subsequent decrease due to reaction with sea salt to form sodium nitrate.

Similar to the primary gaseous species, sulfate and BC started out with high initial mass concentrations and their concentrations decreased very quickly due to dilution. There was no net formation of sulfate mass during plume aging since dilution dominated the evolution of total sulfate mass concentration. Note that our predicted sulfate concentration may be underestimated since we did not include vanadiumcatalyzed sulfate production reactions in our model, as proposed by Ault et al. (2010). The SOA concentrations increased only by about $0.01 \mu \mathrm{g} \mathrm{m}^{-3}$. The lack of production of secondary aerosol mass was a result of the low mixing ratios of oxidants (such as $\mathrm{OH}, \mathrm{O}_{3}$ and $\mathrm{NO}_{3}$ ) in the plume, so that oxidation reactions were largely limited. Our finding is consistent with the results reported in Hobbs et al. (2000), where they did not observe any appreciable increase of the aerosol mass concentration in the ship plume with similar initial conditions and sun light exposure time.

The sensitivity case (start at 06:00 LT) shows a maximum $\mathrm{OH}$ mixing ratio to be 15 times higher than in the original run, and the corresponding SOA mass concentration was enhanced by a similar magnitude. An increase of sulfate mass concentration was observed after $4 \mathrm{~h}$ of simulation, leading to a net production of sulfate mass concentration in the plume of about $2 \mu \mathrm{g} \mathrm{m}^{-3}$. Likewise, the nitrate mass concentration increased to about $6 \mu \mathrm{g} \mathrm{m}^{-3}$. This shows, as expected, that 
Table 4. Error metrics for comparison of measured and simulated aerosol number concentrations. The "only cond.”, “only coag." and "cond. + coag." entries correspond to simulated number concentrations.

\begin{tabular}{llll}
\hline & only cond. & only coag. & cond. + coag. \\
\hline Mean bias & $2.77 \times 10^{11} \mathrm{~m}^{-3}$ & $1.41 \times 10^{10} \mathrm{~m}^{-3}$ & $1.87 \times 10^{10} \mathrm{~m}^{-3}$ \\
Mean error & $2.77 \times 10^{11} \mathrm{~m}^{-3}$ & $1.58 \times 10^{10} \mathrm{~m}^{-3}$ & $1.96 \times 10^{10} \mathrm{~m}^{-3}$ \\
Mean normalized bias & $1096.44 \%$ & $41.38 \%$ & $59.55 \%$ \\
Mean normalized error & $1096.44 \%$ & $51.81 \%$ & $65.11 \%$ \\
\hline
\end{tabular}

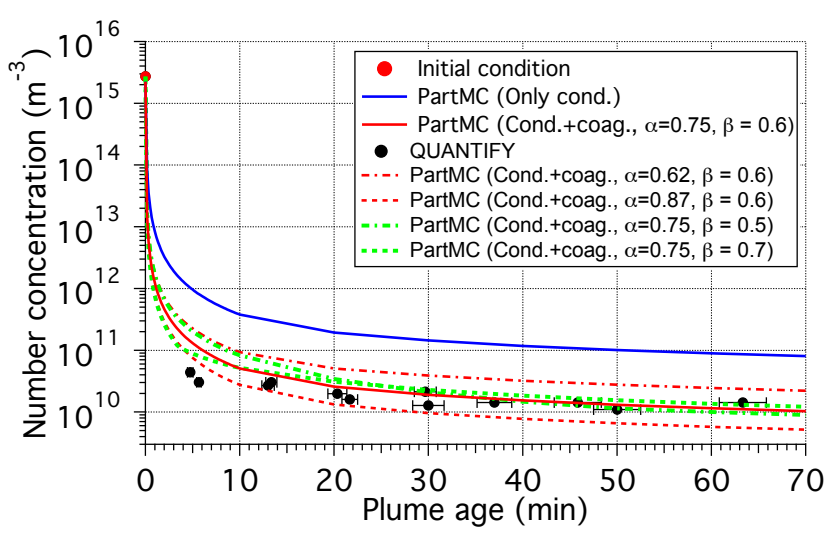

Figure 3. Comparison of modeled number concentrations from the base case with the measured data obtained during the single plume study on 14 June 2007 during the QUANTIFY campaign (size range of 10 to $2000 \mathrm{~nm}$ ). The red dot indicates the initial aerosol number concentration. The horizontal error bars represent the estimated errors in determining plume ages. The four broken lines represent results from sensitivity runs with different sets of values for $\alpha$ and $\beta$

the production of secondary aerosol species is largely determined by the exposure time to sunlight during daytime.

No observations are available that followed the evolution of a particular plume for several hours, hence a quantitative comparison to our simulation results is not possible. However, mixing ratios of $\mathrm{NO}, \mathrm{NO}_{\mathrm{y}}, \mathrm{O}_{3}, \mathrm{SO}_{2}$, and $\mathrm{CO}$ were measured in the shipping corridor on 11 June 2007. These can be used for qualitative comparison with our model results. Observed peak values of $\mathrm{NO}, \mathrm{NO}_{\mathrm{y}}$, and $\mathrm{SO}_{2}$ mixing ratios were 4,12 , and $4 \mathrm{ppb}$, respectively. Observed mixing ratios for $\mathrm{O}_{3}$ and $\mathrm{CO}$ were approximately 35 and $105 \mathrm{ppb}$, respectively. These values are comparable with the model results after approximately $7 \mathrm{~h}$ of simulation time of the sensitivity run (right column in Fig. 2). The mixing ratios of NO and $\mathrm{O}_{3}$ of the base case are somewhat lower because this case extends into the nighttime.

\subsection{Evolution of total number concentration in a single plume}

Figure 3 compares our predicted particle number concentrations to those measured in a ship plume during the single plume study on 14 June 2007. For this figure, only particles in the $10-2000 \mathrm{~nm}$ size range were considered to be consistent with the size range observed by the SMPS (Scanning Mobility Particle Sizer) instrument.

Due to the short encounter time with the ship plume, we assumed that the measurements were conducted at the ship plume center line. The measurements were taken within the first hour after the ship emissions entered the atmosphere, representing a relatively fresh plume. The horizontal error bars on the measured values show the estimated errors in determining plume ages. The estimated relative errors in number concentration are less than $8 \%$, and are not visible in this graph due to the logarithmic scaling of the ordinate. As described in Sect. 3.3 we initialized the model simulations with data from the HERCULES study, indicated here with the red dot.

The modeled time series of number concentration shows a sharp decrease at the beginning due to dilution and coagulation, and then the model results approach the measurements well when coagulation is included (solid red line). When coagulation was not simulated, the total particle number concentration was overestimated by a factor of ten (blue line). A list of error metrics, including mean bias, mean error, mean normalized bias and mean normalized error, is provided in Table 4 for the comparison of simulated and observed number concentrations. Note that since the plume encounter times during the measurements were very short, neither size distribution nor chemical composition data could be obtained from the single plume study.

To explore the sensitivity to the choice of the dispersion parameters $\alpha$ and $\beta$, we conducted four sensitivity runs: two sensitivity runs use the base case value of $\alpha=0.75$, but combine it with $\beta=0.7$ (lower end from the range in Petzold et al., 2008) and $\beta=0.5$, respectively. Two additional sensitivity runs use the base case value of $\beta=0.6$, combined with $\alpha=0.87$ and $\alpha=0.62$, respectively (same range of values used in von Glasow et al., 2003). The simulated number concentration from the sensitivity runs were added to Fig. 3 as broken lines. The parameter combination $(\alpha=0.62$, $\beta=0.6$ ) results in a consistent overprediction of the number concentration by a factor of about 3 , while the combination $(\alpha=0.87, \beta=0.6)$ underpredicts the number concentration after a plume age of $30 \mathrm{~min}$. Differences due to variations of $\beta$ are most noticable during the first $20 \mathrm{~min}$ of the plume. Given the simplicity of the model assumptions, we do not 
attempt to perform a fitting procedure, but conclude from this exercise that using parameter set of our base case $(\alpha=0.75$, $\beta=0.6$ ) captures the observed data reasonably well. Importantly, the spread caused by varying $\alpha$ and $\beta$ is less than the difference between the base case runs with and without coagulation.

\subsection{Evolution of particle size distributions in the shipping corridor}

The aerosol population measured in the shipping corridor can be thought of as the superposition of many ship plumes of different, albeit unknown, ages. This makes it difficult to compare the size distribution measurements quantitatively to the model results, which simulate only one specific plume. Here we attempt to use the observations for a qualitative comparison to see if the PartMC-MOSAIC results are consistent with the observations.

Figure 4 displays the in-plume aerosol number distributions for the base case. The red, green and blue curves represent the measured aerosol distributions for initial, background and ship corridor conditions, while the five black curves are the predicted distributions at plume ages of $100 \mathrm{~s}$, $1200 \mathrm{~s}, 1 \mathrm{~h}, 5 \mathrm{~h}$, and $14 \mathrm{~h}$, respectively. All model results are the averages of an ensemble of 10 runs. The error bars represent the $95 \%$ confidence intervals, only shown for the size distribution at $100 \mathrm{~s}$ as an example. These are vanishingly small for small particle sizes and are somewhat larger for the size range above $500 \mathrm{~nm}$. This is a result of the fact that fewer computational particles are used to represent the population at larger sizes (even though we used the weighted particle algorithm as described in Sect. 3).

To distinguish the effects of coagulation and condensation on particle size distributions, we show the results without simulating coagulation (Fig. 4a, "only cond."), without simulating condensation (Fig. 4b, "only coag"), and the case including all processes (Fig. 4c, "cond. + coag.").

Figure $4 \mathrm{a}$ shows that particle number concentration was significantly reduced due to dilution within the first $100 \mathrm{~s}$, and simultaneously large particles from background were diluted into the plume so that an accumulation and a coarse mode in the size distributions were formed. However, it is obvious that the shape of the size distribution observed in the shipping corridor could not be reproduced when coagulation was neglected. The predicted number concentration of small particles was overestimated compared to the ship corridor measurement. For example, at $14 \mathrm{~h}$, the model result overpredicted the number concentration of particles with sizes $30 \mathrm{~nm}$ by at least one order of magnitude compared to the observed value. When coagulation was additionally included (Fig. 4c), the depletion of the small particles in the volatile mode was captured and the modeled and observed size distributions agreed qualitatively better.

Figure $4 b$ (condensation not simulated) shows a very similar pattern compared to Fig. 4c, which confirms that the
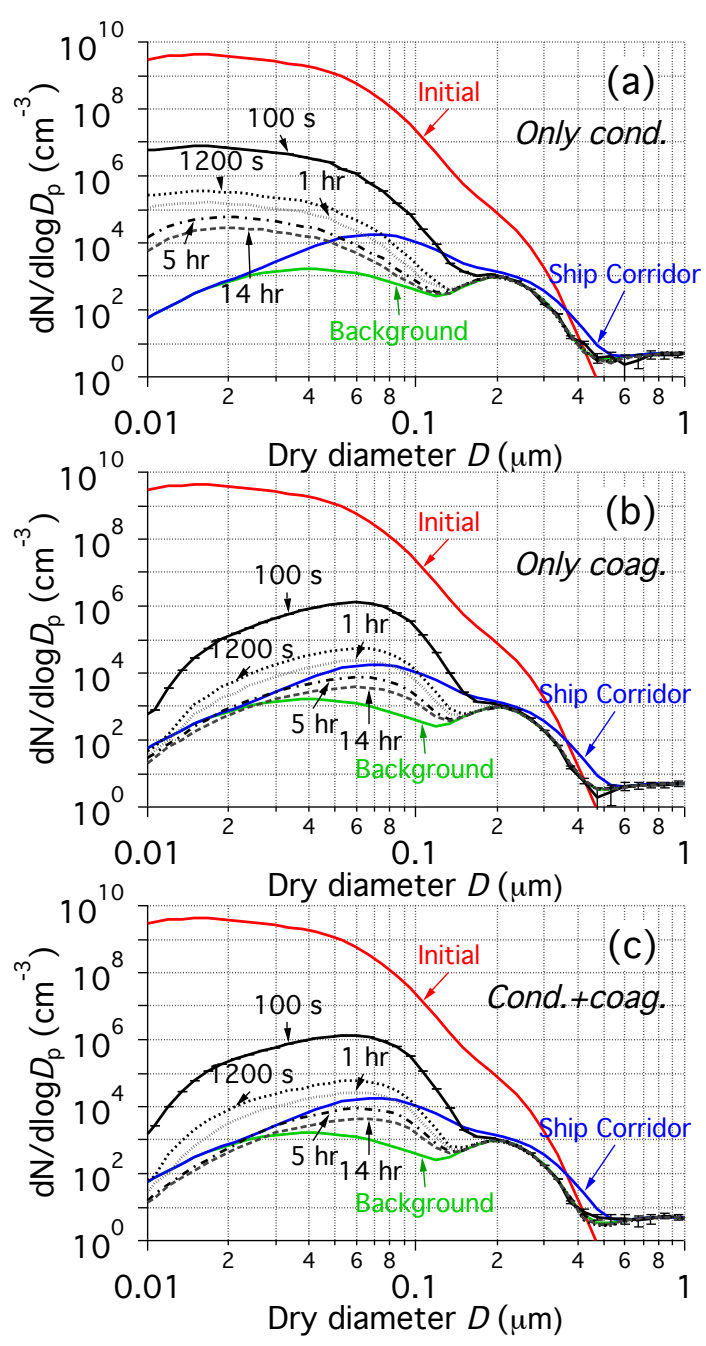

Figure 4. Measured aerosol number distributions for background, initial and ship corridor and modeled results for (a) neglecting coagulation, (b) neglecting condensation and (c) including condensation and coagulation at plume ages of $100 \mathrm{~s}, 1200 \mathrm{~s}, 1 \mathrm{~h}, 5 \mathrm{~h}$, and $14 \mathrm{~h}$ for base case (starting from 14:00 LT). The error bars represent $95 \%$ confidence intervals from 10 ensemble runs (only shown for size distribution at $100 \mathrm{~s}$ as an example).

impact of condensation on the size distributions was small for this case due to the short daylight exposure time and consequently limited amount of photochemical production of secondary aerosol mass, as already pointed out in the discussion of Fig. 2. Therefore, in this case, coagulation and dilution were the driving processes that shaped the size distributions.

To investigate the impact of daylight exposure time further, Fig. 5 shows the in-plume particle size distributions for the simulation of the sensitivity case, with a simulation start of 06:00 LT. The size distributions of plume ages smaller than $1 \mathrm{~h}$ were similar to those for the base case. However in the more aged plume (at 5 and $14 \mathrm{~h}$ ), condensation of secondary aerosol set in, which shifted the particles to larger 
sizes. Condensation in this case greatly altered the size distribution, as shown in Fig. 5a and c. As in Fig. 4, we see that including coagulation led to particle size distributions that are qualitatively in better agreement with the observations.

Overall, Figs. 4 and 5 demonstrate that dilution and coagulation were two major processes dominating the evolution of particles in ship plumes. While dilution significantly reduced the overall in-plume number concentrations, coagulation reduced the number concentrations of the small volatile particles. Moreover, the condensational growth of particles was sensitive to the start of the simulation time. An earlier starting time with a longer, and more intense sun exposure enhanced the production of secondary aerosol mass. Generally, our model results are qualitatively consistent with the observations in the shipping corridor.

\subsection{Impact of coagulation and condensation on particle mixing state}

To elucidate how the mixing state evolved over the course of the simulation of the base case, we show the two-dimensional number distribution as a function of dry diameter and drymass fraction of BC and sulfate in Figs. 6 and 7 at plume ages of $100 \mathrm{~s}, 1 \mathrm{~h}$, and $5 \mathrm{~h}$. The simulation results for the three cases "only cond.", "only coag", and "cond + coag" are placed next to each other for comparison. The definition of the two-dimensional number distribution function is given in Sect. 3.1.

$\mathrm{BC}$ initially resided in the two combustion aerosol modes and also to a small extent in the background aerosol mode. Without coagulation ("only cond.", Fig. 6a, d, and g), the three particle source types were at all times distinctly separated shown as horizontal bands in the two-dimensional number distribution plot. However, when coagulation was included (Fig. 6b, c, e, f, h and i), a continuum of internal mixing states was established very quickly with BC dry-mass fraction ranging from 0 to $12 \%$.

When condensation was not simulated ("only coag."), the initial range of $\mathrm{BC}$ mass fractions from 0 to $12 \%$ was maintained (Fig. 6b, e, and h). When condensation was simulated, the maximum $\mathrm{BC}$ mass fraction decreased over time to values as low as $9 \%$ after $5 \mathrm{~h}$ of simulation, as seen in Fig. 6 i. For the sensitivity case (not shown) this is even more pronounced, and the maximum $\mathrm{BC}$ mass fraction decreased to values as low as $5 \%$.

An analogous evolution of the sulfate mixing state was observed. A continuum of internal mixtures from 0 to $100 \%$ of sulfate dry-mass fraction formed due to coagulation (Fig. 7b, $\mathrm{e}, \mathrm{h}$ and $\mathrm{c}, \mathrm{f}, \mathrm{i}$ ), while for the simulation without coagulation the particles from different sources remained externally mixed (Fig. 7a, d, and g). When condensation was not simulated, ("only coag.", Fig. 7b, e, and h), the range of sulfate mass fractions completely filled the range from 0 to $100 \%$ as the population evolved.
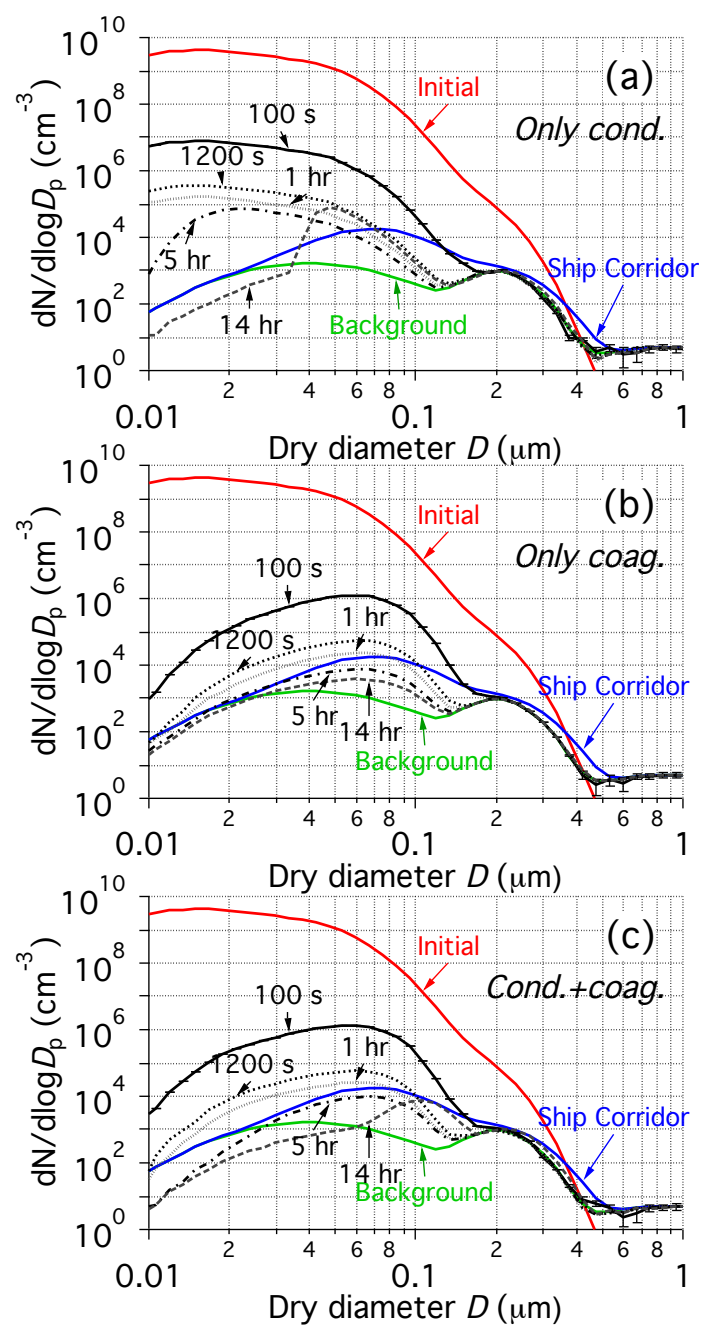

Figure 5. Measured aerosol number distributions for background, initial and ship corridor and modeled results for (a) neglecting coagulation, (b) neglecting condensation and (c) including condensation and coagulation at plume ages of $100 \mathrm{~s}, 1200 \mathrm{~s}, 1 \mathrm{~h}, 5 \mathrm{~h}$, and $14 \mathrm{~h}$ for sensitivity case (starting from 06:00 LT). The error bars represent $95 \%$ confidence intervals from 10 ensemble runs (only shown for size distribution at $100 \mathrm{~s}$ as an example).

An interesting feature of the sulfate mixing state is that after $1 \mathrm{~h}$, the previously horizontal lines representing the particles from various sources became "tilted" (Fig. 7d, f, $\mathrm{g}$ and i). This tilt formed because secondary aerosol mass condensed on the particles, and the resulting change in sulfate dry-mass fraction was relatively larger for small particles compared to large particles. For the volatile-mode particles the tilt was the result of ammonia partitioning into the aerosol phase and thereby reducing the sulfate dry-mass fraction. In our simulation ammonia originated from the evaporation of ammonium nitrate present in the background particles. For the combustion-mode particles the tilt was due to the condensation of sulfuric acid, thereby increasing the sulfate dry-mass fraction. This two-way condensation effect on 

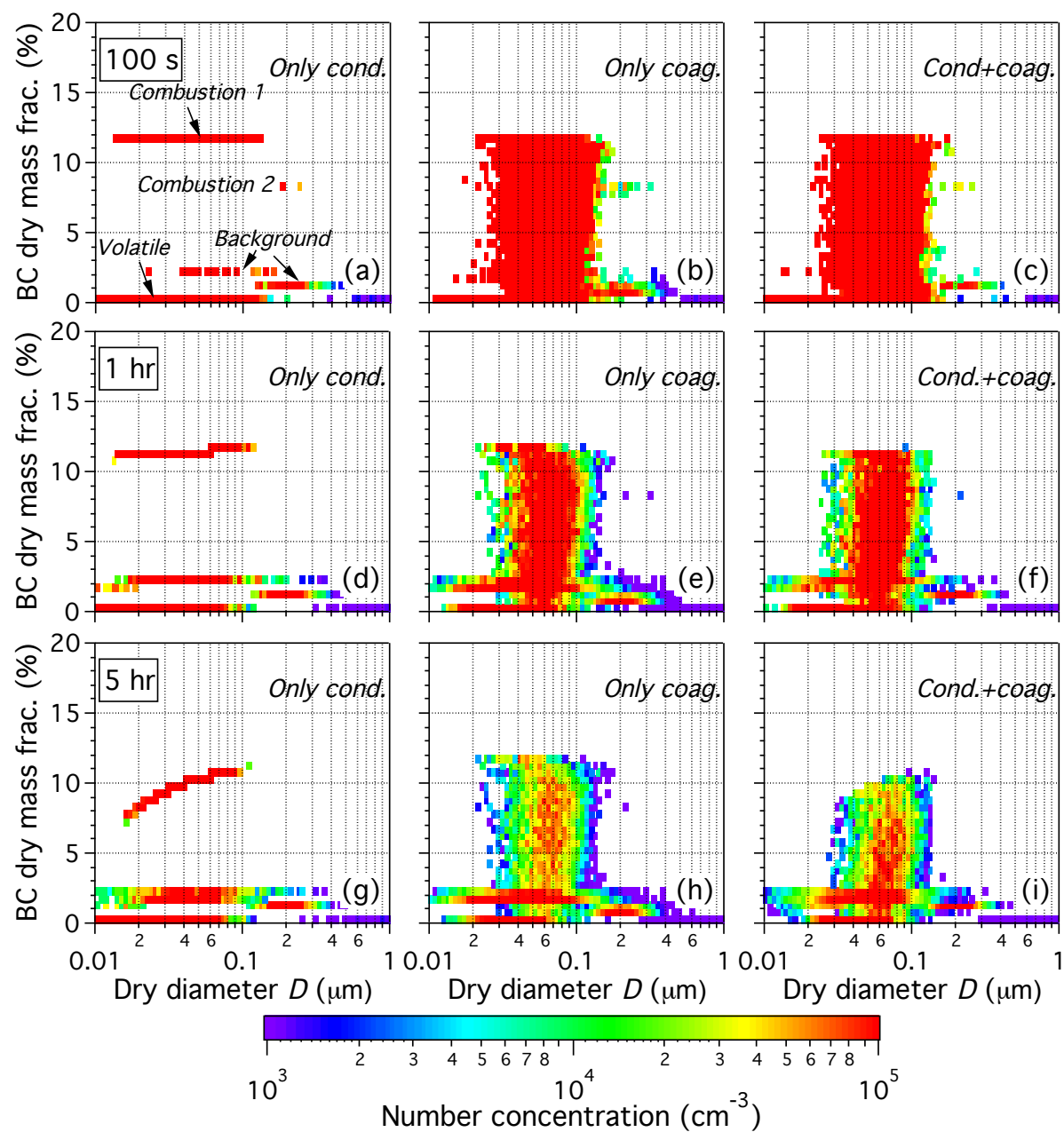

Figure 6. Two-dimensional number distributions $n_{\mathrm{BC}, \mathrm{dry}}(D, w)$ after $100 \mathrm{~s}, 1 \mathrm{~h}$, and $5 \mathrm{~h}$ of simulation for the base case. The two-dimensional number distribution is defined in Eq. (12).

sulfate mixing state was observed for both cases when condensation was included. A similar behavior could also be observed for the BC mixing state (e.g., Fig. $6 \mathrm{~d}$ and g). Note that other secondary aerosol species form, as well as contribute to a change in mixing state, such as secondary organic aerosol and aerosol nitrate, however for the sake of brevity we do not include these results as figures.

\subsection{Cloud condensation nuclei activity}

We will now address the question to what extent the changes in aerosol mixing state translated into changes in $\mathrm{CCN}$ activity. For this purpose it is convenient to display the number distribution $n_{\kappa}(D, \kappa)$ based on Eq. (13), as established in Fierce et al. (2013). Also shown in these graphs are the lines of constant critical supersaturation, which are a function of particle size and hygroscopicity parameter. For a given environmental supersaturation threshold, the particles with critical supersaturations equal to or smaller than the threshold will activate, i.e., these are the particles to the right of the corresponding critical supersaturation line. Figure 8 shows these number distributions for $0 \mathrm{~s}, 100 \mathrm{~s}, 1 \mathrm{~h}$ and $5 \mathrm{~h}$ for the base case simulation, including condensation and coagulation. Initially $(t=0 \mathrm{~s})$, three distinct bands represented the volatile and the two combustion modes. The position of each band was determined by the initial size distribution and composition of each mode determining the overall hygroscopicity. The volatile-mode particles, which contained $100 \%$ sulfate, had the largest hygroscopicity, while hydrophobic combustion-1-mode particles, consisting of POC and BC, were most difficult to activate initially.

At $t=100 \mathrm{~s}$, the space between the three bands had begun to fill out due to coagulation and the associated change of mixing state. As a result, for a subset of the combustion mode particles the hygroscopicity parameter increased. After 1 and $5 \mathrm{~h}$, the average $\kappa$ values of the aerosol population increased further, indicating that a larger fraction of the particles had the potential to become a $\mathrm{CCN}$ for a certain supersaturation 

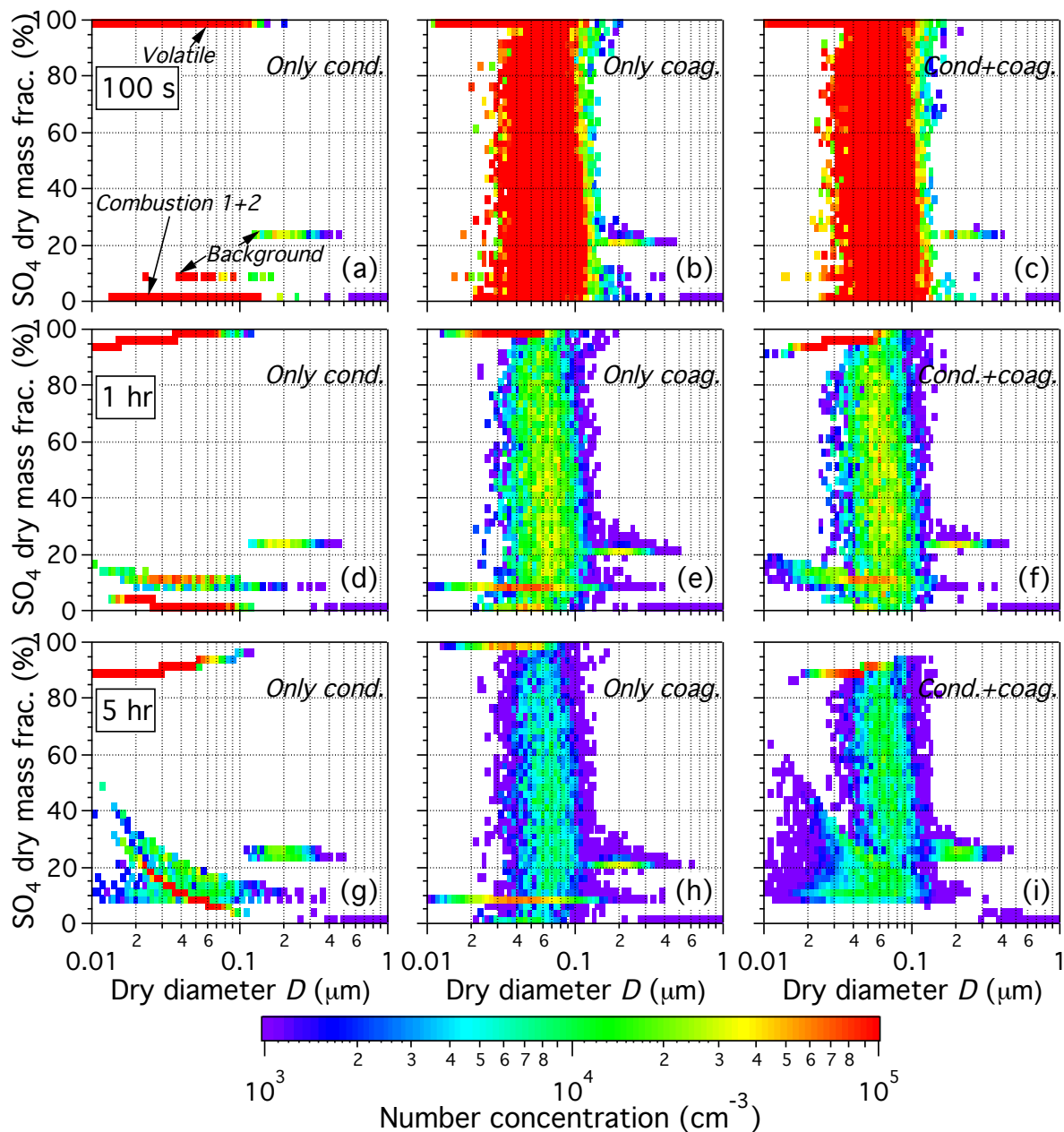

Figure 7. Two-dimensional number distributions $n_{\mathrm{SO}_{4} \text {, dry }}(D, w)$ after $100 \mathrm{~s}, 1 \mathrm{~h}$ and $5 \mathrm{~h}$ of simulation for the base case. The two-dimensional number distribution is defined in Eq. (12).

threshold. Note that particles larger than $0.2 \mu \mathrm{m}$ represented mainly the background particles, as shown in Fig. 4.

Figure 9 shows the $\mathrm{CCN}$ concentration versus critical supersaturation $S$ ranging from 0.01 to $1 \%$ for $0 \mathrm{~s}, 1 \mathrm{~h}, 5 \mathrm{~h}$, and $14 \mathrm{~h}$ for the base case. The three different curves at each time represent the cases where coagulation was not simulated ("only cond.", blue), where condensation was not simulated ("only coag.", green) and where both condensation and coagulation was simulated ("cond. + coag.", red). As the simulation time progressed, the "cond. + coag." case showed consistently larger CCN concentrations than the "only coag." case, but only for supersaturations above a certain threshold (e.g., $S=0.4 \%$ for $t=1 \mathrm{~h}$ ). This is due to the fact that more particles are closer to the activation threshold in the case of higher supersaturations, so adding some hygroscopic material by condensation can have an impact on $\mathrm{CCN}$ concentration. Note that this threshold changed with time. At $t=1 \mathrm{~h}$ it was $S=0.4 \%$, while for $t=5 \mathrm{~h}$ and $t=14 \mathrm{~h}$ it was lowered to $S=0.2 \%$. This is consistent with Fig. 8, which shows that the overall population moved up (i.e., reached higher $\kappa$-values) in the diagram over time.

The total number concentrations for the "only cond." case were about one order of magnitude larger than for the cases that included coagulation. This means that there were more particles available that could act as $\mathrm{CCN}$, but at the same time they all competed for condensable material. The "only cond." case resulted in smaller $\mathrm{CCN}$ concentrations than the other two cases for $S$ less than about $0.7 \%$. This is because most of the combustion particles remained too hydrophobic in the absence of coagulation, and also because there was not enough condensable material available to render these particles hygroscopic enough to activate at supersaturations below $0.7 \%$. However, the CCN concentration of the "only cond." case exceeded the other two cases for $S$ larger than $0.7 \%$ when the growth due to condensation was sufficient to enable activation. We conclude from Fig. 9, that coagulation increased the particle hygroscopicity of initially hydrophobic particles. Coagulation therefore may enhance the $\mathrm{CCN}$ number concentrations, while decreasing the total particle 

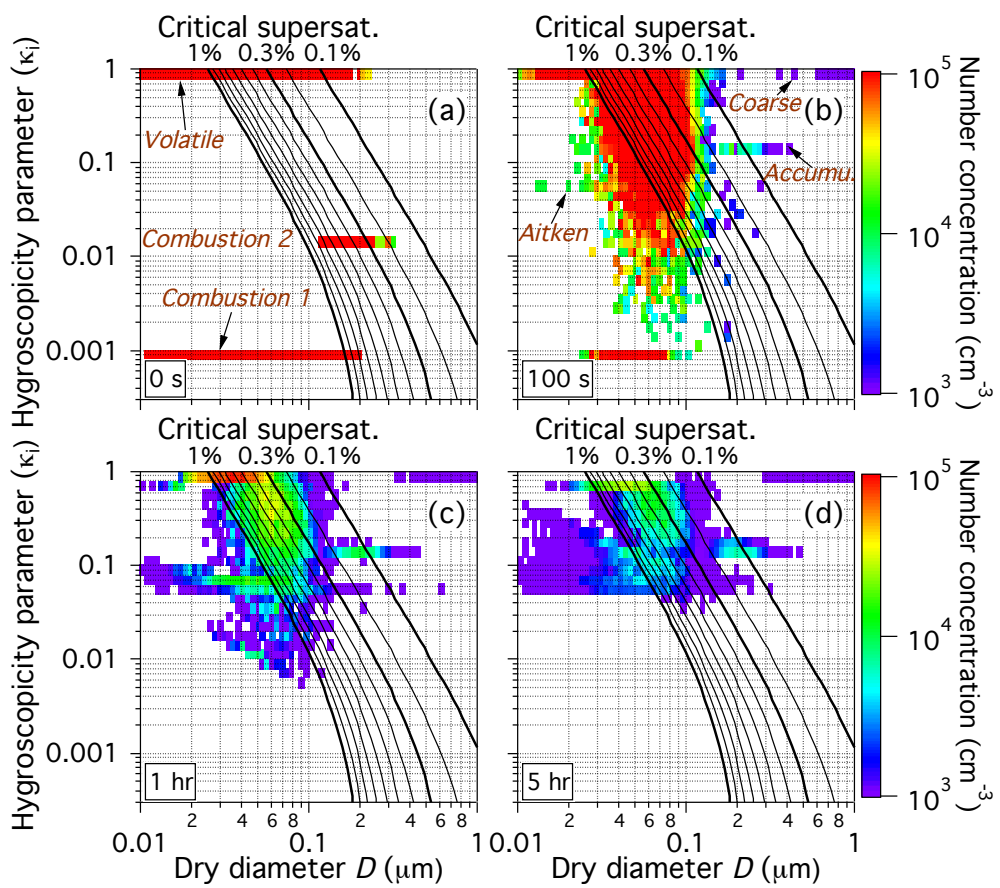

Figure 8. Two-dimensional number distribution $n_{\kappa}(D, \kappa)$ (base case, condensation and coagulation included) at $0 \mathrm{~s}, 100 \mathrm{~s}, 1 \mathrm{~h}$, and $5 \mathrm{~h}$. The 2-D distribution is defined in Eq. (13).

number concentration. Condensation can further enhance the hygroscopicity of particles, leading to an increase of total CCN number concentration if those particles are near the activation threshold.

Interestingly, the three cases resulted in the same $\mathrm{CCN}$ concentration for supersaturation thresholds below $0.2 \%$. The particles that formed $\mathrm{CCN}$ at these low supersaturations were mostly background particles from the accumulation and coarse mode, which have already low critical supersaturations when they enter the simulation. For the base case, the aging of combustion particles by coagulation or condensation was not sufficient to increase their hygroscopicity to the extent that they could activate at such low supersaturation levels.

Similar CCN spectra resulted for the sensitivity case (Fig. 10). However, condensation had a larger impact in this case due to the increased formation of secondary aerosol mass compared to the base case. This can be seen most clearly for low supersaturation thresholds (lower than $0.2 \%$ ) after $14 \mathrm{~h}$ of simulation. For example, at $S=0.2 \%$, the CCN concentration for the "cond. + coag." case was six times that of the "only coag." case, and 3.5 times that of the "only cond." case.

It has been reported that the typical supersaturation for marine stratocumulus is around $0.1 \%$ (Hoppel et al., 1996; Martucci and O'Dowd, 2011). Our results suggest that the impact of ship-emitted particles on marine cloud formation will significantly depend on the time of the day that these particles are exposed to the marine boundary layer.
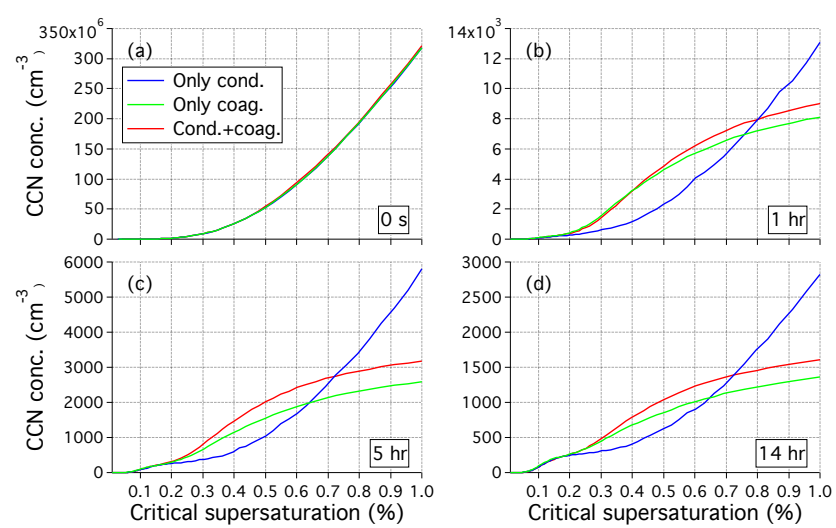

Figure 9. $\mathrm{CCN}$ number concentrations as the function of critical supersaturation at $0 \mathrm{~s}, 1 \mathrm{~h}, 5 \mathrm{~h}$ and $14 \mathrm{~h}$ for the base case.

\section{Conclusions}

In this paper we presented the application of the stochastic aerosol model PartMC-MOSAIC to investigate the evolution of aerosol mixing state and associated changes of $\mathrm{CCN}$ properties in a ship plume. This work provides the first validation study of PartMC, and we showed that the model results agreed well with observed particle number concentrations.

From our process analysis we conclude that for our base case dilution and coagulation were the two major processes influencing the particle distribution and the resulting $\mathrm{CCN}$ activation properties. Dilution reduced the in-plume total 

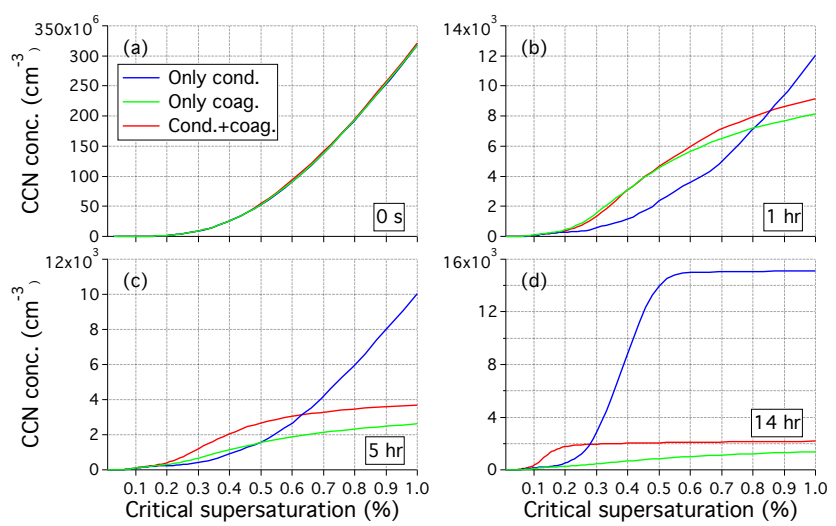

Figure 10. CCN number concentrations as the function of critical supersaturation at $0 \mathrm{~s}, 1 \mathrm{~h}, 5 \mathrm{~h}$ and $14 \mathrm{~h}$ for the sensitivity case.

particle number concentration by about four orders of magnitude within $15 \mathrm{~min}$ from simulation start. Coagulation further reduced the particle number concentration by another order of magnitude and preferentially depleted small volatile particles. To adequately capture the evolution of the size distribution, it was essential to include coagulation.

Moreover, coagulation amongst the particles and condensation of secondary aerosol material altered the particle mixing state in the fresh plume, leading to internally mixed aerosols containing $\mathrm{BC}$ and sulfate within the first $1-2 \mathrm{~min}$ after emission, which evolved further over the course of the simulation. This impacted the CCN properties even for conditions when only small amounts of hygroscopic secondary aerosol mass were formed, as it applied for our base case simulation. However, the impact depended on the supersaturation threshold. For the base case, at the end of the 14-h simulation neglecting coagulation (but simulating condensation) did not have any impact of the CCN concentration below supersaturation values of $0.2 \%$. For supersaturations between $S=0.2 \%$ and $S=0.7 \%$ neglecting coagulation resulted in a reduction of the $\mathrm{CCN}$ concentration, for example by 37 and $28 \%$ for supersaturation thresholds of 0.3 and $0.6 \%$, respectively. For supersaturations larger than $0.7 \%$ neglecting coagulation resulted in an overestimation of $\mathrm{CCN}$ concentration, about $75 \%$ for $S=1 \%$. On the other hand, neglecting condensation, but simulating coagulation, also did not impact the $\mathrm{CCN}$ concentrations below $0.2 \%$. It resulted in an underestimation of $\mathrm{CCN}$ concentrations for larger supersaturations, e.g., $18 \%$ for $S=0.6 \%$. From this we conclude that, for the base case conditions, coagulation had a larger impact on $\mathrm{CCN}$ concentrations than condensation.
This picture changed somewhat for conditions with higher formation rates of secondary aerosol mass. This can be seen for low supersaturation thresholds (lower than about $0.3 \%$ ) after $14 \mathrm{~h}$ of simulation. For example, at $S=0.2 \%$, neglecting coagulation resulted in a $70 \%$ decrease of $\mathrm{CCN}$ concentrations, whereas neglecting condensation resulted in a $83 \%$ decrease. While neglecting condensation resulted in lower $\mathrm{CCN}$ concentrations over the whole range of supersaturations, neglecting coagulation led to a large increase in CCN concentrations for supersaturations larger than $0.3 \%$. For example, for $S=0.6 \%$ the CCN concentration for the "only cond." case is seven times that of the "coag. + cond." case.

We also explored the role of new particle formation for the evolution of the ship plume aerosol population using the nucleation parameterization by Kuang et al. (2008). For the base case the influence of nucleation on $\mathrm{CCN}$ concentration was limited because there was not enough condensable material available to grow the particles formed by nucleation to CCN-relevant sizes. For the sensitivity case, after the newly-formed particles were exposed to about $10 \mathrm{~h}$ of growth, the $\mathrm{CCN}$ concentration was increased by about one order of magnitude when nucleation was included as long as the supersaturation threshold was sufficiently high, in our case higher than $0.3 \%$.

Acknowledgements. J. Tian, N. Riemer, and M. West acknowledge funding from the National Science Foundation (NSF) under Grant CMG-0934491. This publication was made possible by US EPA grant 83504201 . Its contents are solely the responsibility of the grantee and do not necessarily represent the official views of the US EPA. Further, US EPA does not endorse the purchase of any commercial products or services mentioned in the publication. Part of this work was supported by the EU FP6 Integrated Project QUANTIFY (Quantifying the Climate Impact of Global and European Transport Systems; http://www.pa.op.dlr.de/quantify/).

Edited by: C. H. Song 

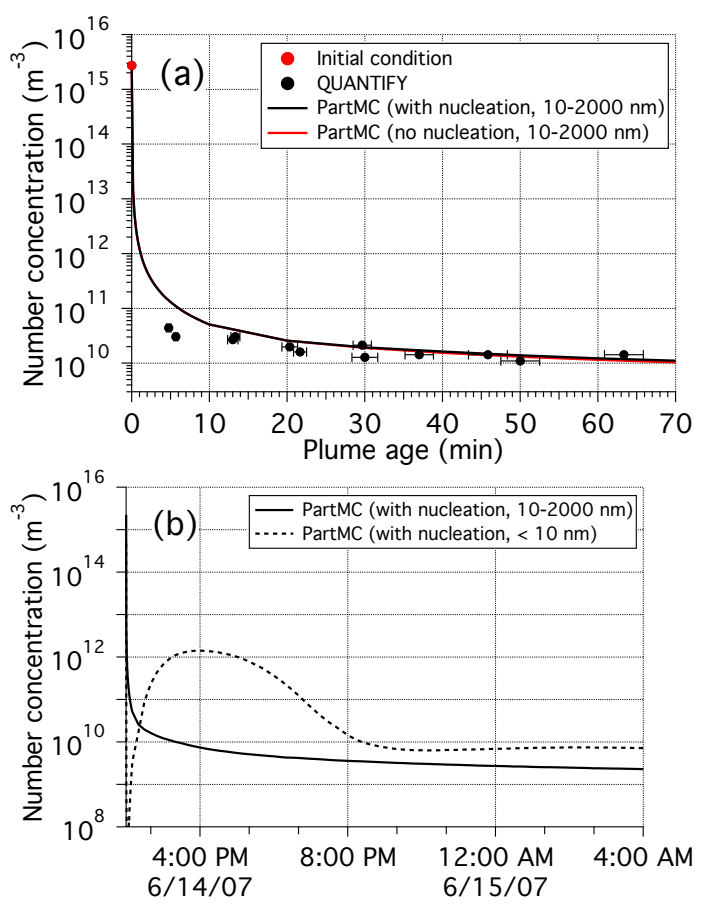

Figure A1. (a) Comparison of simulated number concentrations from the base case with nucleation to the observed data obtained during the single plume study on 14 June 2007 during the QUANTIFY campaign. The red dot indicates the initial aerosol number concentration. The horizontal error bars represent the estimated errors in determining plume ages. (b) Simulated number concentrations from the base case during the entire simulation period with nucleation for particles in the range of 10-2000 nm and below $10 \mathrm{~nm}$.

\section{Appendix A: Simulations including nucleation}

Here we describe the results for the base case and for the sensitivity case when nucleation was included. As before we first present the results for the number concentrations, then the size distributions, and finally the resulting $\mathrm{CCN}$ spectra.

On a process level, a nucleation event can impact CCN concentration in several ways: (1) nucleation produces a large number of additional particles, which can grow into CCN directly if enough condensable material is present; (2) if the condensable material is limited, then the competition for this material between the large near-CCN-active particles and the nucleated small particles could actually lead to less CCN; and (3) the nucleated particles can coagulate with other particles, which could potentially render them $\mathrm{CCN}$ active, increasing the $\mathrm{CCN}$ concentration. When including the treatment of nucleation as described in Sect. 2.2, we found that nucleation did occur in the ship plume, but that the newly formed particles did not contribute significantly to $\mathrm{CCN}$ except in particular situations when condensational growth was prevalent for several hours.

Figure A1 shows the evolution of the base-case number concentration when nucleation was simulated. When
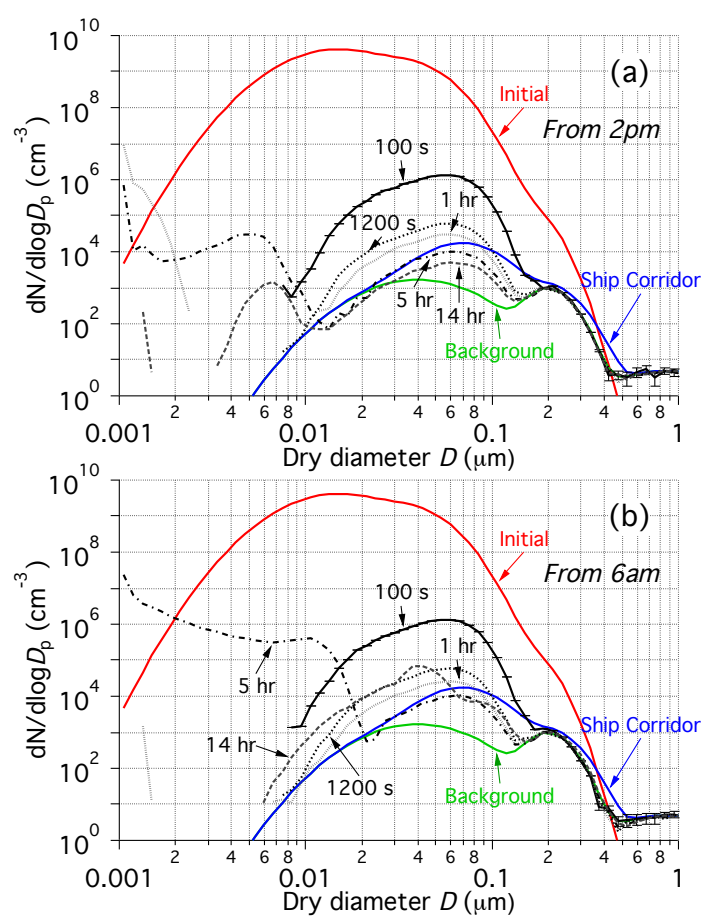

Figure A2. Measured aerosol number distributions for background, initial and ship corridor and modeled results with nucleation for (a) base case (from 14:00 LT) (b) sensitivity case (from 06:00 LT) at plume ages of $100 \mathrm{~s}, 1200 \mathrm{~s}, 1 \mathrm{~h}, 5 \mathrm{~h}$ and $14 \mathrm{~h}$. The error bars represent $95 \%$ confidence intervals from five ensemble runs (only shown for size distribution at $100 \mathrm{~s}$ as an example).

including only the particles from the observed $10-2000 \mathrm{~nm}$ size range, the results are the same as for the corresponding case without nucleation (Fig. A1a). However, nucleation did affect the number concentration of particles smaller than $10 \mathrm{~nm}$. Figure A1b shows the evolution of number concentration for particles in the $10-2000 \mathrm{~nm}$ range, as well as for those below $10 \mathrm{~nm}$, for the entire $14 \mathrm{~h}$ of simulation period. The concentration of nucleated particles (which are assigned the size of $1 \mathrm{~nm}$ when they enter the simulation) reached the maximum of $10^{12} \mathrm{~m}^{-3}$ at 16:00 LT ( $2 \mathrm{~h}$ after simulation), then gradually decreased to around $10^{10} \mathrm{~cm}^{-3}$ at 20:00 LT. The concentration of 10-2000 nm particles, however, did not increase, which indicated that the nucleated particles did not grow to sizes larger than $10 \mathrm{~nm}$ during the plume evolution.

The evolution of the size distributions is shown in Fig. A2 for both the base case (Fig. A2a) and the sensitivity case (Fig. A2b). Note that we extended the diameter axis down to $1 \mathrm{~nm}$ to capture the full range of sizes. In both cases, nucleated particles formed a distinct mode below $10 \mathrm{~nm}$, and the number concentrations in this mode gradually decreased due to coagulation and dilution, and moved to larger sizes due to condensation during the plume evolution. While for the base case the nucleated particles form a distinct mode that remains below $10 \mathrm{~nm}$ in size, for the sensitivity case they 

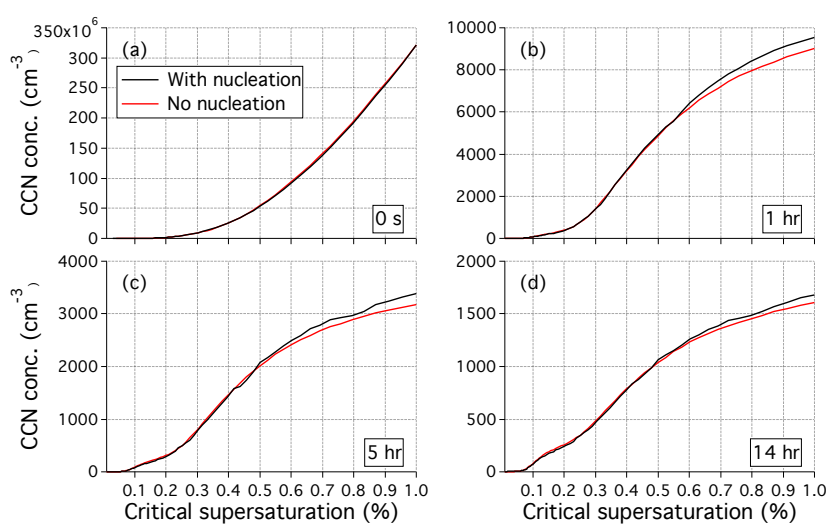

Figure A3. CCN number concentrations as the function of critical supersaturation at $0 \mathrm{~s}, 1 \mathrm{~h}, 5 \mathrm{~h}$ and $14 \mathrm{~h}$ for the base case, comparing the simulation with nucleation enabled to the simulation with nucleation disabled.

grow beyond this size, which has an appreciable impact on CCN concentrations as shown below.

Figure A3 shows the comparison of the $\mathrm{CCN}$ spectrum with and without nucleation for the base case. Coagulation and condensation were included for these simulations. When nucleation is included, the $\mathrm{CCN}$ concentration remains unchanged for supersaturations below $0.6 \%$. For higher supersaturations, the simulation with nucleation yields somewhat higher $\mathrm{CCN}$ concentrations. For example, at $5 \mathrm{~h}$, nucleation increased the CCN concentration at $S=0.6 \%$ from 2422 to $2496 \mathrm{~cm}^{-3}$ for the base case, and from 3053 to $3200 \mathrm{~cm}^{-3}$ for the sensitivity case. This is consistent with the findings described above.
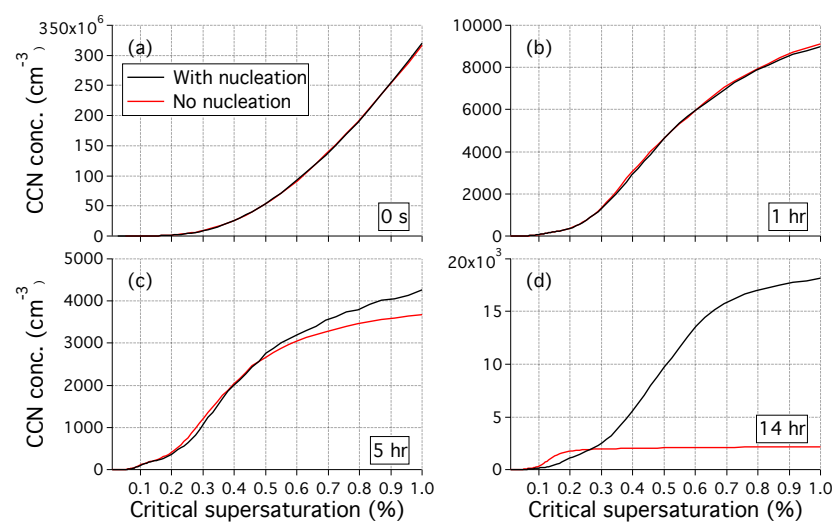

Figure A4. CCN number concentrations as the function of critical supersaturation at $0 \mathrm{~s}, 1 \mathrm{~h}, 5 \mathrm{~h}$ and $14 \mathrm{~h}$ for the sensitivity case, comparing the simulation with nucleation enabled to the simulation with nucleation disabled.

For the sensitivity case, including nucleation led to much larger differences after several hours of simulation. This can be seen in Fig. A4d $(t=14 \mathrm{~h})$, where the CCN concentration for supersaturations above $0.3 \%$ increased by about one order of magnitude when nucleation was included. Interestingly, for this time, we also observe that for supersaturation lower than $0.3 \%$ the $\mathrm{CCN}$ concentration decreased when nucleation was included. This counterintuitive result is a reflection of competition for condensable material between the larger near-CCN-active particles and the nucleated particles. 


\section{References}

Agrawal, H., Eden, R., Zhang, X., Fine, P. M., Katzenstein, A., Miller, J. W., Ospital, J., Teffera, S., and Cocker III, D. R.: Primary particulate matter from ocean-going engines in the southern California air basin, Environ. Sci. Technol., 43, 5398-5402, doi:10.1021/es8035016, 2009.

Ault, A. P., Moore, M. J., Furutani, H., and Prather, K. A.: Impact of emissions from the Los Angeles port region on San Diego air quality during regional transport events, Environ. Sci. Technol., 43, 3500-3506, doi:10.1021/es8018918, 2009.

Ault, A. P., Gaston, C. J., Wang, Y., Dominguez, G., Thiemens, M. H., and Prather, K. A.: Characterization of the single particle mixing state of individual ship plume events measured at the Port of Los Angeles, Environ. Sci. Technol., 44, 1954-1961, doi:10.1021/es902985h, 2010.

Capaldo, K., Corbett, J., Kasibhatla, P., Fischbeck, P., and Pandis, S.: Effects of ship emissions on sulphur cycling and radiative climate forcing over the ocean, Nature, 400, 743-746, 1999.

Ching, J., Riemer, N., and West, M.: Impacts of black carbon mixing state on black carbon nucleation scavenging: Insights from a particle-resolved model, J. Geophys. Res.-Atmos., 117, D23209, doi:10.1029/2012JD01826, 2012.

Coakley, J., Bernstein, R., and Durkee, P.: Effect of shipstack effluents on cloud reflectivity, Science, 237, 1020-1022, doi:10.1126/science.237.4818.1020, 1987.

Coggon, M. M., Sorooshian, A., Wang, Z., Metcalf, A. R., Frossard, A. A., Lin, J. J., Craven, J. S., Nenes, A., Jonsson, H. H., Russell, L. M., Flagan, R. C., and Seinfeld, J. H.: Ship impacts on the marine atmosphere: insights into the contribution of shipping emissions to the properties of marine aerosol and clouds, Atmos. Chem. Phys., 12, 8439-8458, doi:10.5194/acp-12-84392012, 2012.

Conover, J.: Anomalous cloud lines, J. Atmos. Sci., 23, 778-785, doi:10.1175/1520-0469(1966)023<0778:ACL>2.0.CO;2, 1966.

Cooper, D.: Exhaust emissions from ships at berth, Atmos. Environ., 37, 3817-3830, doi:10.1016/S1352-2310(03)00446-1, 2003.

Corbett, J. J., Winebrake, J. J., Green, E. H., Kasibhatla, P., Eyring, V., and Lauer, A.: Mortality from ship emissions: a global assessment, Environ. Sci. Technol., 41, 8512-8518, doi:10.1021/es071686z, 2007.

DeVille, R., Riemer, N., and West, M.: Weighted Flow Algorithms (WFA) for stochastic particle coagulation, J. Comput. Phys., 230, 8427-8451, doi:10.1016/j.jcp.2011.07.027, 2011.

Dominguez, G., Jackson, T., Brothers, L., Barnett, B., Nguyen, B., and Thiemens, M. H.: Discovery and measurement of an isotopically distinct source of sulfate in Earth's atmosphere, P Natl. Acad. Sci. USA, 105, 12769-12773, doi:10.1073/pnas.0805255105, 2008.

Durkee, P., Chartier, R., Brown, A., Trehubenko, E., Rogerson, S., Skupniewicz, C., Nielsen, K., Platnick, S., and King, M.: Composite ship track characteristics, J. Atmos. Sci., 57, 2542-2553, doi:10.1175/1520-0469(2000)057<2542:CSTC>2.0.CO;2, 2000a.

Durkee, P., Noone, K., and Bluth, R.: The Monterey Area Ship Track experiment, J. Atmos. Sci., 57, 2523-2541, doi:10.1175/1520-0469(2000)057<2523:TMASTE>2.0.CO;2, 2000b.
Endresen, O., Sorgard, E., Sundet, J., Dalsoren, S., Isaksen, I., Berglen, T., and Gravir, G.: Emission from international sea transportation and environmental impact, J. Geophys. Res.Atmos., 108, 4560, doi:10.1029/2002JD002898, 2003.

Erlick, C., Russell, L., and Ramaswamy, V.: A microphysics-based investigation of the radiative effects of aerosol-cloud interactions for two MAST Experiment case studies, J. Geophys. Res.Atmos., 106, 1249-1269, doi:10.1029/2000JD900567, 2001.

Eyring, V., Köhler, H., van Aardenne, J., and Lauer, A.: Emissions from international shipping: 1 . The last 50 years, J. Geophys. Res.-Atmos., 110, D17305, doi:10.1029/2004JD005619, 2005.

Eyring, V., Stevenson, D. S., Lauer, A., Dentener, F. J., Butler, T., Collins, W. J., Ellingsen, K., Gauss, M., Hauglustaine, D. A., Isaksen, I. S. A., Lawrence, M. G., Richter, A., Rodriguez, J. M., Sanderson, M., Strahan, S. E., Sudo, K., Szopa, S., van Noije, T. P. C., and Wild, O.: Multi-model simulations of the impact of international shipping on Atmospheric Chemistry and Climate in 2000 and 2030, Atmos. Chem. Phys., 7, 757-780, doi:10.5194/acp-7-757-2007, 2007.

Eyring, V., Isaksen, I. S. A., Berntsen, T., Collins, W. J., Corbett, J. J., Endresen, O., Grainger, R. G., Moldanova, J., Schlager, H., and Stevenson, D. S.: Transport impacts on atmosphere and climate: shipping, Atmos. Environ., 44, 4735-4771, doi:10.1016/j.atmosenv.2009.04.059, 2010.

Ferek, R., Hegg, D., Hobbs, P., Durkee, P., and Nielsen, K.: Measurements of ship-induced tracks in clouds off the Washington coast, J. Geophys. Res.-Atmos., 103, 23199-23206, doi:10.1029/98JD02121, 1998.

Fierce, L. M.., Riemer, N., and Bond, T. C.: When is cloud condensation nuclei activity sensitive to particle characteristics at emission?, J. Geophys. Res.-Atmos., 118, 1-13, doi:10.1002/2013JD020608, 2013.

Frick, G. and Hoppel, W.: Airship measurements of ship's exhaust plumes and their effect on marine boundary layer clouds, J. Atmos. Sci., 57, 2625-2648, doi:10.1175/15200469(2000)057<2625:AMOSSE>2.0.CO;2, 2000.

Ghan, S., Laulainen, N., Easter, R., Wagener, R., Nemesure, S., Chapman, E., Zhang, Y., and Leung, R.: Evaluation of aerosol direct radiative forcing in MIRAGE, J. Geophys. Res.-Atmos., 106, 5295-5316, doi:10.1029/2000JD900502, 2001.

González, Y., Rodriguez, S., Guerra Garcia, J. C., Luis Trujillo, J., and Garcia, R.: Ultrafine particles pollution in urban coastal air due to ship emissions, Atmos. Environ., 45, 4907-4914, doi:10.1016/j.atmosenv.2011.06.002, 2011.

Healy, R. M., O'Connor, I. P., Hellebust, S., Allanic, A., Sodeau, J. R., and Wenger, J. C.: Characterisation of single particles from in-port ship emissions, Atmos. Environ., 43, 64086414, 2009.

Hobbs, P. V., Garrett, T. J., Ferek, R. J., Strader, S. R., Hegg, D. A., Frick, G. M., Hoppel, W. A., Gasparovic, R. F., Russell, L. M., Johnson, D. W., O’Dowd, C., Durkee, P. A., Nielsen, K. E., and Innis, G.: Emissions from ships with respect to their effects on cloud, J. Atmos. Sci., 57, 2570-2590, 2000.

Hoppel, W., Frick, G., and Fitzgerald, J.: Deducing droplet concentration and supersaturation in marine boundary layer clouds from surface aerosol measurements, J. Geophys. Res.-Atmos., 101, 26553-26565, 1996. 
Jacobson, M. Z., Wilkerson, J. T., Naiman, A. D., and Lele, S. K.: The effects of aircraft on climate and pollution, Part I: Numerical methods for treating the subgrid evolution of discrete size- and composition-resolved contrails from all commercial flights worldwide, J. Comput. Phys., 230, 5115-5132, doi:10.1016/j.jcp.2011.03.031, 2011.

Kaiser, J. C., Riemer, N., and Knopf, D. A.: Detailed heterogeneous oxidation of soot surfaces in a particle-resolved aerosol model, Atmos. Chem. Phys., 11, 4505-4520, doi:10.5194/acp-11-45052011, 2011.

Kasper, A., Aufdenblatten, S., Forss, A., Mohr, M., and Burtscher, H.: Particulate emissions from a low-speed marine diesel engine, Aerosol Sci. Tech., 41, 24-32, doi:10.1080/02786820601055392, 2007.

Keene, W. C., Stutz, J., Pszenny, A. A. P., Maben, J. R., Fischer, E. V., Smith, A. M., von Glasow, R., Pechtl, S., Sive, B. C., and Varner, R. K.: Inorganic chlorine and bromine in coastal New England air during summer, J. Geophys. Res.-Atmos., 112, D10S12, doi:10.1029/2006JD007689, 2007.

Kuang, C., McMurry, P. H., McCormick, A. V., and Eisele, F. L.: Dependence of nucleation rates on sulfuric acid vapor concentration in diverse atmospheric locations, J. Geophys. Res.-Atmos., 113, D10209, doi:10.1029/2007JD009253, 2008.

Kulmala, M., Laakso, L., Lehtinen, K. E. J., Riipinen, I., Dal Maso, M., Anttila, T., Kerminen, V.-M., Hõrrak, U., Vana, M., and Tammet, H.: Initial steps of aerosol growth, Atmos. Chem. Phys., 4, 2553-2560, doi:10.5194/acp-4-2553-2004, 2004.

Lauer, A., Eyring, V., Hendricks, J., Jöckel, P., and Lohmann, U.: Global model simulations of the impact of ocean-going ships on aerosols, clouds, and the radiation budget, Atmos. Chem. Phys., 7, 5061-5079, doi:10.5194/acp-7-5061-2007, 2007.

Lawrence, $\mathrm{M}$. and Crutzen, P.: Influence of $\mathrm{NO}_{\mathrm{x}}$ emissions from ships on tropospheric photochemistry and climate, Nature, 402, 167-170, doi:10.1038/46013, 1999.

Liu, P. F., Zhao, C. S., Göbel, T., Hallbauer, E., Nowak, A., Ran, L., Xu, W. Y., Deng, Z. Z., Ma, N., Mildenberger, K., Henning, S., Stratmann, F., and Wiedensohler, A.: Hygroscopic properties of aerosol particles at high relative humidity and their diurnal variations in the North China Plain, Atmos. Chem. Phys., 11, 34793494, doi:10.5194/acp-11-3479-2011, 2011.

Lucas, D. D. and Akimoto, H.: Evaluating aerosol nucleation parameterizations in a global atmospheric model, Geophys. Res. Lett., 33, L10808, doi:10.1029/2006GL025672, 2006.

Ma, N., Zhao, C. S., Müller, T., Cheng, Y. F., Liu, P. F., Deng, Z. Z., $\mathrm{Xu}$, W. Y, Ran, L., Nekat, B., van Pinxteren, D., Gnauk, T., Müller, K., Herrmann, H., Yan, P., Zhou, X. J., and Wiedensohler, A.: A new method to determine the mixing state of light absorbing carbonaceous using the measured aerosol optical properties and number size distributions, Atmos. Chem. Phys., 12, 2381-2397, doi:10.5194/acp-12-2381-2012, 2012.

Martucci, G. and O'Dowd, C. D.: Ground-based retrieval of continental and marine warm cloud microphysics, Atmos. Meas. Tech., 4, 2749-2765, doi:10.5194/amt-4-2749-2011, 2011.

Moldanová, J., Fridell, E., Popovicheva, O., Demirdjian, B., Tishkova, V., Faccinetto, A., and Focsa, C.: Characterisation of particulate matter and gaseous emissions from a large ship diesel engine, Atmos. Environ., 43, 2632-2641, 2009.
Murphy, S. M., Agrawal, H., Sorooshian, A., Padro, L. T., Gates, H., Hersey, S., Welch, W. A., Jung, H., Miller, J. W., Cocker III, D. R., Nenes, A., Jonsson, H. H., Flagan, R. C., and Seinfeld, J. H.: Comprehensive simultaneous shipboard and airborne characterization of exhaust from a modern container ship at sea, Environ. Sci. Technol., 43, 4626-4640, doi:10.1021/es802413j, 2009.

O’Dowd, C. D. and De Leeuw, G.: Marine aerosol production: a review of the current knowledge, Philos. T. Roy. Soc. A, 365, 1753-1774, doi:10.1098/rsta.2007.2043, 2007.

Osborne, S., Johnson, D., Bower, K., and Wood, R.: Modification of the aerosol size distribution within exhaust plumes produced by diesel-powered ships, J. Geophys. Res.-Atmos., 106, 9827-9842, 2001.

Penkett, S. A., Blake, N. J., Lightman, P., Marsh, A. R. W., Anwyl, P., and Butcher, G.: The seasonal variation of nonmethane hydrocarbons in the free troposphere over the North Atlantic Ocean: Possible evidence for extensive reaction of hydrocarbons with the nitrate radical, J. Geophys. Res.-Atmos., 98, 2865-2885, doi:10.1029/92JD02162, 1993.

Peters, K., Stier, P., Quaas, J., and Graß1, H.: Aerosol indirect effects from shipping emissions: sensitivity studies with the global aerosol-climate model ECHAM-HAM, Atmos. Chem. Phys., 12, 5985-6007, doi:10.5194/acp-12-5985-2012, 2012.

Petters, M. D. and Kreidenweis, S. M.: A single parameter representation of hygroscopic growth and cloud condensation nucleus activity, Atmos. Chem. Phys., 7, 1961-1971, doi:10.5194/acp-71961-2007, 2007.

Petzold, A., Hasselbach, J., Lauer, P., Baumann, R., Franke, K., Gurk, C., Schlager, H., and Weingartner, E.: Experimental studies on particle emissions from cruising ship, their characteristic properties, transformation and atmospheric lifetime in the marine boundary layer, Atmos. Chem. Phys., 8, 2387-2403, doi:10.5194/acp-8-2387-2008, 2008.

Petzold, A., Weingartner, E., Hasselbach, J., Lauer, P., Kurok, C., and Fleischer, F.: Physical properties, chemical composition and cloud forming potential of particulate emissions from a marine diesel engine at various load conditions, Environ. Sci. Technol., 44, 3800-3805, 2010.

Pierce, J. R. and Adams, P. J.: Uncertainty in global CCN concentrations from uncertain aerosol nucleation and primary emission rates, Atmos. Chem. Phys., 9, 1339-1356, doi:10.5194/acp-91339-2009, 2009.

Porch, W., Borys, R., Durkee, P., Gasparovic, R., Hooper, W., Hindman, E., and Nielsen, K.: Observations of ship tracks from ship-based platforms, J. Appl. Meteorol., 38, 69-81, doi:10.1175/1520-0450(1999)038<0069:OOSTFS>2.0.CO;2, 1999.

Riemer, N., West, M., Zaveri, R. A., and Easter, R. C.: Simulating the evolution of soot mixing state with a particleresolved aerosol model, J. Geophy. Res., 114, D09202, doi:10.1029/2008JD011073, 2009.

Riemer, N., West, M., Zaveri, R. A., and Easter, R. C.: Estimating black carbon aging time-scales with a particle-resolved aerosol model, Aerosol Sci., 41, 143-158, 2010.

Russell, L., Seinfeld, J., Flagan, R., Ferek, R., Hegg, D., Hobbs, P., Wobrock, W., Flossmann, A., O’Dowd, C., Nielsen, K., and Durkee, P.: Aerosol dynamics in ship tracks, J. Geophys. Res.Atmos., 104, 31077-31095, doi:10.1029/1999JD900985, 1999. 
Russell, L., Noone, K., Ferek, R., Pockalny, R., Flagan, R., and Seinfeld, J.: Combustion organic aerosol as cloud condensation nuclei in ship tracks, J. Atmos. Sci., 57, 2591-2606, doi:10.1175/1520-0469(2000)057<2591:COAACC>2.0.CO;2, 2000.

Sander, R. and Crutzen, P.: Model study indicating halogen activation and ozone destruction in polluted air masses transported to the sea, J. Geophys. Res.-Atmos., 101, 9121-9138, doi:10.1029/95JD03793, 1996.

Schell, B., Ackermann, I., Hass, H., Binkowski, F., and Ebel, A.: Modeling the formation of secondary organic aerosol within a comprehensive air quality model system, J. Geophys. Res.Atmos., 106, 28275-28293, doi:10.1029/2001JD000384, 2001.

Shon, Z.-H., Madronich, S., Song, S.-K., Flocke, F. M., Knapp, D. J., Anderson, R. S., Shetter, R. E., Cantrell, C. A., Hall, S. R., and Tie, X.: Characteristics of the NO- $\mathrm{NO}_{2}-\mathrm{O}_{3}$ system in different chemical regimes during the MIRAGE-Mex field campaign, Atmos. Chem. Phys., 8, 7153-7164, doi:10.5194/acp8-7153-2008, 2008.

Sinha, P., Hobbs, P., Yokelson, R., Christian, T., Kirchstetter, T., and Bruintjes, R.: Emissions of trace gases and particles from two ships in the southern Atlantic Ocean, Atmos. Environ., 37, 2139-2148, doi:10.1016/S1352-2310(03)00080-3, 2003.

Song, C., Chen, G., and Davis, D.: Chemical evolution and dispersion of ship plumes in the remote marine boundary layer: investigation of sulfur chemistry, Atmos. Environ., 37, 2663-2679, doi:10.1016/S1352-2310(03)00198-5, 2003.

Spracklen, D. V., Carslaw, K. S., Kulmala, M., Kerminen, V.-M., Sihto, S.-L., Riipinen, I., Merikanto, J., Mann, G. W., Chipperfield, M. P., Wiedensohler, A., Birmili, W., and Lihavainen, H.: Contribution of particle formation to global cloud condensation nuclei concentrations, Geophys. Res. Lett., 35, L06808, doi:10.1029/2007GL033038, 2008.

Stockwell, W. R., Lawson, C. V., Saunders, E., and Wendy, S. G.: A review of tropospheric chemistry and gas-phase chemical mechanisms for air quality modeling, Atmosphere, 3, 1-32, doi:10.3390/atmos3010001, 2012.

Twomey, S., Howell, H., Wojciech, T. A., and Conover, J.: Comments on anomalous cloud lines, J. Atmos. Sci., 25, 333 334, doi:10.1175/1520-0469(1968)025<0333:COCL>2.0.CO;2, 1968.
Verheggen, B. and Mozurkewich, M.: Determination of nucleation and growth rates from observation of a $\mathrm{SO}_{2}$ induced atmospheric nucleation event, J. Geophys. Res., 107, 4123, doi:10.1029/2001JD000683, 2002.

Vogt, R., Crutzen, P., and Sander, R.: A mechanism for halogen release from sea-salt aerosol in the remote marine boundary layer Nature, 383, 327-330, doi:10.1038/383327a0, 1996.

von Glasow, R., Lawrence, M. G., Sander, R., and Crutzen, P. J.: Modeling the chemical effects of ship exhaust in the cloudfree marine boundary layer, Atmos. Chem. Phys., 3, 233-250, doi:10.5194/acp-3-233-2003, 2003.

Westervelt, D. M., Pierce. J. R., and Adams, P. J.: Analysis of feedbacks between nucleation rate, survival probability and cloud condensation nuclei formation, Atmos. Chem. Phys., 13, 3217532228, doi:10.5194/acpd-13-32175-2013, 2013.

Winebrake, J. J., Corbett, J. J., Green, E. H., Lauer, A., and Eyring, V.: Mitigating the health impacts of pollution from oceangoing shipping: An assessment of lowsulfur fuel mandates, Environ. Sci. Technol., 43, 4776-4782, doi:10.1021/es803224q, 2009.

Yli-Juuti, T., Nieminen, T., Hirsikko, A., Aalto, P. P., Asmi, E., Hõrrak, U., Manninen, H. E., Patokoski, J., Dal Maso, M., Petäjä, T., Rinne, J., Kulmala, M., and Riipinen, I.: Growth rates of nucleation mode particles in Hyytiälä during 20032009: variation with particle size, season, data analysis method and ambient conditions, Atmos. Chem. Phys., 11, 12865-12886, doi:10.5194/acp-11-12865-2011, 2011,

Zaveri, R. A. and Peters, L.: A new lumped structure photochemical mechanism for large-scale applications, J. Geophys. Res.Atmos., 104, 30387-30415, 1999.

Zaveri, R. A., Easter, R., and Peters, L.: A computationally efficient multicomponent equilibrium solver for aerosols (MESA), J. Geophys. Res.-Atmos., 110, D24203, doi:10.1029/2004JD005618, 2005a.

Zaveri, R. A., Easter, R., and Wexler, A.: A new method for multicomponent activity coefficients of electrolytes in aqueous atmospheric aerosols, J. Geophys. Res.-Atmos., 110, D02201, doi:10.1029/2004JD004681, 2005b.

Zaveri, R. A., Easter, R. C., Fast, J. D., and Peters, L. K.: Model for Simulating Aerosol Interactions and Chemistry (MOSAIC), J. Geophys. Res., 113, D13204, doi:10.1029/2007JD008782, 2008. 